\title{
DIE SARKOPHAGWERKSTÄTTEN VON AQUINCUM UND BRIGETIO
}

\author{
ERWIN POCHMARSKI
}

Institut für Archäologie, Karl-Franzens-Universität, Graz

E-Mail: erwin.pochmarski@uni-graz.at

\begin{abstract}
Workshops of sarcophagi in Aquincum and Brigetio. This contribution deals with problems of chronology, iconography and decoration of the sarcophagi of Aquincum and Brigetio. For the chronology the inscriptions, which name the cities as municipium or colonia are more helpful than the dates of the stationing of the legio I adiutrix and the legio II adiutrix respectively. Regarding the iconography of the many sarcophagi with erotes in the fields on both sides of the inscription the type of this representations is decisive.
\end{abstract}

Keywords: Sarcophagi, Brigetio, Aquincum, sarcophagi with erotes, Norican-Pannonian volute ornament

Unter den Sarkophagwerkstätten der römischen Provinz Pannonia ${ }^{1}$ sind jene von Brigetio und Aquincum die bei Weitem fruchtbarsten. Das hängt sicher mit der langjährigen Stationierung von Legionen in diesen beiden Städten zusammen. In Brigetio, das nach der Provinzteilung unter Trajan zunächst zur Provinz Pannonia superior gehörte und erst ab 214 n. Chr. zur Pannonia inferior, ${ }^{2}$ war seit den letzten Regierungsjahren Trajans ${ }^{3}$ oder ab Beginn der Regierung Hadrians ${ }^{4}$ bis in die Spätantike die legio I adiutrix stationiert. Im Gefolge von L. Barkóczi ${ }^{5}$ konnte ich für Brigetio insgesamt 54 Sarkophage zusammenstellen. ${ }^{6}$ Ein größerer Teil der Sarkophaginschriften (13) bezieht sich auf Angehörige der legio I adiutrix, ${ }^{7}$ was wegen der langen, im Wesentlichen nicht unterbrochenen Stationierungsdauer der Legion in Brigetio für chronologische Fragen allerdings wenig hergibt. Nur in den Fällen, in denen auf Sarkophaginschriften ein Beiname der legio I adiutrix genannt wird - pia fidelis Antoniniana oder pia fidelis Severiana -, erhalten wir nähere Anhaltspunkte für eine Datierung in die Regierungszeit von Caracalla und Elagabal bzw. Alexander Severus. ${ }^{8}$

${ }^{1}$ Gemeint ist die ungeteilte Provinz Pannonia als Ganzes, die unter Trajan zwischen 103-107 n. Chr. in die Provinzen Pannonia superior und Pannonia inferior zweigeteilt und unter Diocletian nach 293 n. Chr. in die Provinzen Pannonia I, Savia, Valeria und Pannonia II viergeteilt wurde; vgl. Mócsy 1962, 586-588; Mócsy 1974, 92-99, 273-276; FITZ 1993, 371-372; FITZ 1995, 1175-1183.

${ }^{2}$ Vgl. SchöN-WitTKe 2000, 254. Erst 214 n. Chr. wurde Brigetio zur Pannonia inferior geschlagen: SCHÖN-WITTKE 2000, 255 (irrtümlich jedoch BURIAN 1997, 777, wo Brigetio undifferenziert der Pannonia inferior zugewiesen wird).

${ }^{3}$ Mócsy 1962, 616; Barkóczi, in BARKóczI-Mócsy 1976, 89.

${ }^{4}$ RitTERLiNG 1925, 1392.
5 BARKócZi 1951, 40-42, 55-57, Nr. 91-127; Barkóczi, in BARKÓCZI-MócSY 1976, Nr. 506, 512, 514, 516, 517, 521, 524, 528, $529,533,536,540,544,545,552,553,554,557,562,568,569,572$, 573, 575, 576, 583, 584, 587, 588, 590, 595, 602, 603, 619; Barkóczi, in BARKÓCZI-SOPRONI 1981, Nr. 636, 637, 676, 679, 706, 707, 712, 737, 737 bis.

${ }^{6}$ Pochmarski 2001, 205-209, Nr. 1-54.

${ }^{7}$ Pochmarski 2001, 205-209, Nr. 1, 4, 8, 18, 19, 20, 21, 23, 27, 29A, 40, 47, 49. In letzter Zeit haben HARL-LőRINCZ 2002 (Nr. $5,7,11,14,21,24,32,36,40,46,59,61,62$ ) die in Komárno aufbewahrten Sarkophage neu zusammengestellt, ohne allerdings über die von Pochmarski 2001, 205-209 erstellte Materialsammlung (bis auf zwei Sarkophagdeckel) hinauszugehen.

${ }^{8}$ Vgl. Pochmarski 2001, 201. 
In Aquincum, der Hauptstadt der Pannonia inferior seit der Provinzteilung, war seit der spätflavischen Zeit die legio II adiutrix stationiert, die allerdings $89 \mathrm{n}$. Chr. oder bald danach temporär von der legio IV Flavia abgelöst wurde. ${ }^{9}$ Die legio II adiutrix war zusammen mit der legio I adiutrix an den Dakerkriegen und dem Partherkrieg Trajans beteiligt; beide kehrten im Anschluss daran nach Aquincum bzw. Brigetio zurück. ${ }^{10}$ In der Folge wurde die legio II adiutrix bei der Beteiligung an Expeditionen in Aquincum jeweils von der legio IV Flavia ersetzt - so z. B. 161-167 n. Chr., als sie für den Partherkieg des Lucius Verus abgezogen wurde ${ }^{11}$ oder unter Septimius Severus, ${ }^{12}$ mit dem sie $202 \mathrm{n}$. Chr. aus dem Partherkrieg nach Aquincum zurückkehrte. ${ }^{13} \mathrm{Im}$ Rahmen der Arbeiten zu den pannonischen Sarkophagen konnte der Verfasser mit Unterstützung der ungarischen Kolleginnen und Kollegen ${ }^{14}$ bisher insgesamt 81 Sarkophage mit der Herkunft aus Aquincum zusammenstellen. ${ }^{15}$ Von den Inschriften lassen sich nicht weniger als 27 Beispiele auf die legio II adiutrix beziehen, wobei allerdings in einigen (fünf) fraglichen Fällen die legio II adiutrix nicht ausdrücklich genannt wird. ${ }^{16}$ Aber auch hier ergibt sich aus den Inschriften aufgrund der Legionsgeschichte lediglich ein wenig hilfreicher terminus post quem für die spätflavische Zeit, den man allenfalls auf die Zeit ab 167 n. Chr. bzw. 202 n. Chr. einengen kann, als die Legion aus den Partherkriegen zurückkehrte.

Bereits im Fall der Sarkophage von Brigetio waren die Inschriften, welche Bezug auf das municipium Brigetio nehmen, von größerem Wert als die reinen Militärinschriften, ${ }^{17}$ denn Brigetio wurde entweder bereits unter Septimius Severus, ${ }^{18}$ jedenfalls aber unter Caracalla, zum municipium ${ }^{19}$ und zu einem nicht näher bestimmbaren Zeitpunkt um die Mitte des 3. Jahrhunderts n. Chr. zur colonia erhoben. ${ }^{20}$ Aus der Nennung des municipium Brigetio ergibt sich damit ein verhältnismäßig knapper Zeitraum für eine Ansetzung des betreffenden Sarkophags. Ähnlich verhält es sich auch mit Aquincum, das allerdings bereits unter Hadrian municipium Aelium wird ${ }^{21}$ und unter Septimius Severus 194 n. Chr. zur colonia Septimia Aquincum erhoben wird. ${ }^{22}$ Von den Sarkophaginschriften betreffen allerdings nur fünf ${ }^{23}$ die colonia Aquincum, woraus sich aber ein guter terminus post quem ergibt. Schließlich können von den Inschriften noch jene als Datierungshilfe herangezogen werden, die kaiserliche Gentilizien aufweisen. In Brigetio sind das 18 Beispiele, ${ }^{24}$ wobei sich zeigt, dass die Aurelii besonders stark vertreten sind, ${ }^{25}$ die in der Mehrzahl auf Caracalla zu beziehen sein dürften ${ }^{26}$ und damit wieder einen terminus post quem nahe legen. Ähnlich verhält es sich mit Aquincum, wo sich 16 Beispiele für Kaisergentilizien feststellen lassen, ${ }^{27}$ bei denen es sich wieder zum weitaus überwiegenden Teil um Aurelii handelt. ${ }^{28}$

Nach diesen allgemeinen Daten soll in der Folge eine vergleichende Darstellung der Sarkophage von Brigetio und Aquincum versucht werden. Während in Brigetio Sarkophage mit stadtrömischem Anstrich wie mythologische Sarkophage oder Girlandensarkophage fast gänzlich fehlen, ${ }^{29}$ sind aus Aquincum wenigstens je ein mythologischer Sarkophag ${ }^{30}$ und ein Girlandensarkophag ${ }^{31}$ erhalten. Der mythologische Sarkophag hat auf der Vorderseite beiderseits der mit dem sog. norisch-pannonischen Volutenornament eingefassten tabula wohl Erotenfiguren ${ }^{32}$ oder Heroenfiguren, ${ }^{33}$ während auf der linken Nebenseite Orest und Pylades vor Iphigenie und auf der

${ }^{9}$ Mócsy 1962, 614; Mócsy 1974, 86.

${ }^{10}$ Mócsy 1962, 615-616; Mócsy 1974, 99.

${ }^{11}$ Mócsy 1962, 616; Mócsy 1974, 183.

${ }^{12}$ Mócsy 1962, 616; Mócsy 1974, 198.

${ }^{13}$ Mócsy 1974, 201.

${ }^{14}$ M. Németh und K. Szirmai vom Aquincum-Museum, M. Nagy vom Ungarischen Nationalmuseum sowie B. Lőrincz $(\dagger)$, denen ich zu herzlichem Dank verpflichtet bin.

${ }^{15}$ Weitere sechs Exemplare finden sich in der von O. Harl und F. Harl zusammengestellten Bilddatenbank ubi-erat-lupa, allerdings ohne Abbildung.

${ }^{16}$ Liste der Sarkophage aus Aquincum (in der Folge als „Liste“ abgekürzt): Nr. 10, 11, 12, 13, 16, 17, 20, 21, 26, 27, 31?, 32?, 33?, 34, 35, 39, 43, 44, 52?, 55, 61 (Abb. 8), 66, 71, 76, 79?, 80, 81. Die Nummerierung entspricht der im Anhang beigegebenen neuen Liste der Sarkophage aus Aquincum.

${ }^{17}$ Pochmarski 2001, Nr. 3, 9, 10, 15, 22, 46, 50.

${ }^{18}$ Barkóczi, in: BARKóczi-Mócsy 1976, 89; vgl. PochMARSKI 2001, 201

${ }^{19}$ Mócsy 1962, 600; Mócsy 1974, 221.
${ }^{20}$ Mócsy 1974, 225.

${ }^{21}$ Mócsy 1962, 598-599; MócSy 1974, 141.

22 Mócsy 1962, 599; Mócsy 1974, 218.

${ }^{23}$ Liste: Nr. 11, 16, 25, 49, 79.

${ }^{24}$ Pochmarski 2001, Nr. 4, 6, 10, 13, 14, 15, 18, 19, 20, 23, 25, 26, 29A, 30, 35, 43, 47, 49.

${ }^{25}$ Pochmarski 2001, Nr. 6, 14, 15, 18, 20, 25, 26, 29A, 30, $35,43,47$.

${ }^{26}$ BARKÓCZI 1964, 272, 294; BARKÓCZI 1965, 246.

${ }^{27}$ Liste: Nr. 16, 18, 32, 33, 34, 35, 43, 49, 52, 53, 55, 61, $64,75,77,80$

${ }^{28}$ Liste: Nr. 18, 32, 33, 34, 35, 43, 49, 52, 53, 61, 75, 77, 80

${ }^{29}$ Pochmarski 2001, 207, Nr. 21 ist ein Sarkophag mit dionysischen Figuren in den Seitenfeldern.

${ }^{30}$ Budapest, MNM, Inv.-Nr. 13.1882.99: Nr. 1 der Liste.

${ }^{31}$ Budapest, Aquincum-Museum, Inv.-Nr. 64.10.21: Nr. 2 der Liste.

32 Vgl. Pochmarski 1998, 191, Nr. 72.

${ }^{33}$ Vgl. HaRL, Lupa, Nr. 117 (F. Harl). 
rechten die Schindung des Marsyas dargestellt sind. ${ }^{34}$ Die übrigen von G. Koch mit aller Vorsicht als mögliche Hauptseite eines Sarkophags bzw. als Nebenseiten von Sarkophagen genannten Reliefs ${ }^{35}$ - Mars und Rhea Silvia bzw. Theseus und Ariadne, Menelaos und Helena sowie Theseus und Minotauros - sind wohl eher als Bestandteile von Grabbauten anzusehen. ${ }^{36}$

$\mathrm{Zu}$ Recht hat G. Koch auch den Girlandensarkophag aus Aquincum als ungewöhnlich angesprochen. ${ }^{37}$ Beiderseits der tabula steht jeweils ein Volutenkrater, aus dem ein Weinstock mit Trauben wächst. Vor diesen Gefäßen ist jeweils eine Blattgirlande aufgehängt, die an Rosetten befestigt ist und von diesen im Bogen bzw. senkrecht herabfällt. Vergleichsbeispiele für die Art der Aufhängung lassen sich am ehesten an unteritalischen Sarkophagen der spätantoninischen Zeit beobachten, an denen die Blattgirlanden seitlich an Balustern aufgehängt sind. ${ }^{38}$

Eine sowohl in Brigetio als auch in Aquincum außerordentlich häufige Form von Darstellungen auf pannonischen Sarkophagen sind Graberoten in den Feldern beiderseits der tabula. ${ }^{39}$ Es lassen sich 17 Sarkophage mit Graberoten aus Brigetio ${ }^{40}$ gleich vielen aus Aquincum ${ }^{41}$ gegenüberstellen. Bei der Analyse der Motive können mehrere Darstellungsformen von Graberoten unterschieden werden. ${ }^{42}$ Eine erste Gruppe umfasst Eroten, welche mit beiden Händen oder mit nur einer Hand nach der tabula greifen; ${ }^{43}$ dabei gehen die Eroten zur Mitte oder sie stehen zur Mitte gewendet. Die zweite, größere Gruppe zeigt Graberoten mit einer Fackel. Innerhalb dieser Gruppe haben auf einem Teil der Sarkophage die Eroten die Fackel erhoben und halten sie mit beiden Händen; sie können zur Mitte oder nach außen bewegt sein oder ruhig stehen. ${ }^{44}$ Auf der Mehrzahl der Sarkophage halten die Graberoten aber die Fackel gesenkt, wobei sich der Eros mit dem Ellbogen oder mit der Achsel auf die Fackel stützt. Die Graberoten stehen meist mit überkreuzten Beinen da, seltener einfach mit äußerem Stand- und innerem Spielbein (Abb. 1).45

Ein bisher noch nicht erfasstes Exemplar $(A b b .2)^{46}$ zeigt in den mit einem profilierten Bogen abgeschlossenen Seitenfeldern die mit überkreuzten Beinen stehenden Graberoten. Der rechte Eros hat die Fackel unter die rechte Achsel geklemmt und hält sie mit der Rechten, während er die Linke quer über die Brust zur rechten Schulter geführt hat. Der linke Graberos hat die Fackel aufgestützt und hält sie mit dem schräg vor den Oberkörper geführten rechten Arm und mit der gesenkten Linken.

Nun hat der Autor für die pannonischen Sarkophage zu zeigen versucht, dass die Graberoten zwei Altersstufen angehören, einer eher kindlichen und einer jugendlichen. ${ }^{47}$ Untersuchungen an Eroten mit Girlanden auf norischen und pannonischen Grabstelen und Grabbaureliefs hatten zu dem gleichen Ergebnis geführt. ${ }^{48}$ Auch an den stadtrömischen Girlandensarkophagen lassen sich kindliche und jugendliche Eroten unterscheiden, ${ }^{49}$ wobei sich ein Wandel von den kindlichen zu den jugendlichen Eroten abzeichnet. Auch für die Jahreszeitensarkophage konnte dieser Wandel von puttenhaften, kleinen zu schlanken, größeren Jahreszeiteneroten festgestellt werden.$^{50}$ Diesen ikonographischen Wandel möchte ich anhand des stadtrömischen Materials frühestens in die spätantoninische Zeit datieren; fest greifbar ist der veränderte Alterstypus dort erst ab der frühseverischen Zeit. ${ }^{51}$

${ }^{34}$ Vgl. Koch, in Koch-Sichtermann 1982, 326, Anm. 45.

${ }^{35} \mathrm{KoCH}-$ Sichtermann 1982, 326, Anm. 46-49.

${ }^{36}$ Vgl. HARL, Lupa, Nr. 2889 (Mars und Rhea Silvia) bzw. Nr. 2990 (Theseus und Ariadne), Nr. 2991 (Menelaos und Helena), Nr. 2988 (Theseus und Minotauros).

${ }^{37}$ Koch, in Koch-Sichtermann 1982, 325, Anm. 41.

${ }^{38}$ Vgl. HerdeJÜrgen 1996, Kat. 163, Taf. 107.3; Kat. 182, Taf. 105.2 .

${ }^{39} \mathrm{Vgl}$. Koch, in: Koch-Sichtermann 1982, 325, Anm. 37; PoCHMARSKI 1998, 182-200; PoCHMARSKi 2001, 201-202, 205-206, Nr. 1-17.

${ }^{40}$ Pochmarski 1998, 182-191, Nr. 1, 2, 12, 31, 32, 35, 38, 42, 43, 61, 62, 63 (Liste unvollständig); POCHMARSKi 2001, 205-206, Nr. $1-17$.

${ }^{41}$ Pochmarski 1998, 182-191, Nr. 5, 6, 8, 13, 14, 15, 16 , $18,46,47,48,49,50,51,52,73$ (aus der Liste ist die Nr. 17 gestrichen, da es sich um eine Grabtafel und nicht um einen Sarkophag handelt); vgl. die hier beigegebene Liste: Nr. 4-20, die um ein Exemplar. (Nr. 9: Aquincum-Museum, Inv. 66.11.69) erweitert ist.

42 Pochmarski 1998, 191-193.
${ }^{43}$ Brigetio: 5 Exemplare: PochMARski 1998, Nr. 1, 2, 31, 32, 35; Pochmarski 2001, Nr. 2, 3, 5, 6, 7; keine Beispiele aus Aquincum.

${ }^{44}$ Brigetio: 1 Exemplar: Pochmarski 1998, Nr. 37; PoCHMARSKI 2001, Nr. 8; Aquincum: 3 Exemplare: POCHMARSKI 1998, Nr. 5, 6, 8; Liste: Nr. 4, 5, 6 (1. Feld).

${ }^{45}$ Brigetio: 4 Exemplare: Pochmarski 1998, Nr. 12, 41, 42, 43; POCHMARSKi 2001, Nr. 4, 10, 11, 12; Aquincum: 15 Exemplare: PoCHMARSKI 1998, Nr. 8 (r. Feld), 13, 14, 15, 16, 17 (auszuscheiden), 18, 46, 47, 48, 49, 50, 51, 52, 73; Liste: 6 (r. Feld) (Abb. 1), 7, 8, 9 (neues Stück), (Abb. 2), 10, 11, 12, 13, 14, 15, 16, 17, 18, 19, 20.

Für die Reproduktionserlaubnis der ursprünglich für das Sarkophag-Corpus gemachten Aufnahmen hat der Autor der Direktion des Aquincum-Museums (P. Zsidi) sehr herzlich zu danken.

${ }^{46}$ Aquincum-Museum, Inv. 66.11.69; Liste: Nr. 9 (Abb. 2).

${ }^{47}$ PoCHMARSKI 1998, 196-200; PoCHMARSKI 2001, 201-202.

48 PoCHMARSKI 1983-1984, 268-272; PoCHMARSKI 19851986, 253-262

${ }^{49}$ Herdejürgen 1996, 57-64.

${ }^{50}$ KrANZ 1984a, 133-138.

${ }^{51}$ Pochmarski 1988, 196-198. 
Im Gefolge dieser Überlegungen wurden die Sarkophage mit Eroten in Pannonien von mir in zwei Gruppen unterteilt: solche mit einem kindlichen, eher rundlichen Graberos und solche mit einem knabenhaften, jugendlichen Graberos. ${ }^{52}$ Mithilfe von aussagekräftigen Inschriften konnte die sich abzeichnende Veränderung des Erotentypus frühestens in die frühseverische Zeit datiert werden, aus der sich sowohl kindliche als auch jugendliche Erotenfiguren erhalten haben. Betrachtet man vor diesem Hintergrund die Sarkophage aus Brigetio und Aquincum, so lässt sich zeigen, dass von den 15 näher bestimmbaren Sarkophagen mit Eroten aus Brigetio nur drei die Darstellung kindlicher Erotenfiguren aufweisen, ${ }^{53}$ während die übrigen zwölf jugendliche Eroten wiedergeben. ${ }^{54}$ Von den aus Aquincum stammenden Sarkophagen mit Graberoten haben dagegen acht den kindlichen Eros zum Gegenstand, ${ }^{55}$ während neun den jugendlichen Erostypus verwenden. ${ }^{56}$ Daraus ergibt sich, dass die Zahl der Sarkophage mit Graberoten aus vorseverischer Zeit in Brigetio vergleichsweise sehr gering ist, während den Löwenanteil die ab frühseverischer Zeit üblich werdenden jugendlichen Eroten ausmachen; in Aquincum findet sich hingegen in der mittel- bis spätantoninischen Zeit noch eine Anzahl von Sarkophagen mit kindlichen Eroten.

Die nächste, thematisch gut fassbare Gruppe von Sarkophagen sind solche mit Soldatenfiguren in zumindest einem der Felder seitlich von der tabula. Diese Darstellungen lassen sich zum Teil aufgrund der von den Soldaten getragenen Uniform - sagum mit Scheibenfibel, tunica manicata, braccae, Ringschnallencingulum - zeitlich näher einordnen: ${ }^{57}$ Diese Teile der Uniform wurden von $\mathrm{H}$. Ubl überzeugend mit der ab der späten Regierungszeit des Septimius Severus, vor allem aber ab Caracalla, üblichen Dienstuniform der römischen Soldaten in Verbindung gebracht..$^{58}$

Aus Brigetio haben sich drei Sarkophage von Angehörigen der legio I adiutrix mit Soldatendarstellungen erhalten, ${ }^{59}$ für die sich aufgrund der antiquarischen Indizien und des Gentilnomen Aurelius eine Datierung in die Zeit ab Caracalla ergibt. Diesen drei Sarkophagen stehen zwei aus Aquincum gegenüber, ${ }^{60}$ die näher betrachtet werden sollen.

In dem linken Seitenfeld des einen Sarkophags aus Aquincum $(A b b .4 a-b)^{61}$ ist ein Togatus in der Vorform der toga contabulata dargestellt, ${ }^{62}$ der mit den Fingern seiner Rechten in den Saum der Toga greift (Abb.4), während er in der Linken ein Gefäß (?) hält. Bei der Darstellung im rechten Seitenfeld handelt es sich hingegen um einen Soldaten, der die kurze, langärmelige Tunika (tunica manicata) trägt, die mit einem Ringschnallencingulum gegürtet ist; darüber ist er mit dem an der rechten Schulter mit einer Scheibenfibel zusammengehaltenen sagum bekleidet; in der linken Hand hält der Soldat eine Schriftrolle (volumen), auf die er die Finger der rechten Hand im Schwuroder wohl in einem deiktischen Gestus legt; ${ }^{63}$ über seiner linken Schulter erscheint sein Horn (cornu), auf das die Inschrift explizit Bezug nimmt, die den Soldaten als Hornbläser (cornicen) der legio II adiutrix anspricht. Die antiquarischen Details ergeben zusammen mit dem kaiserlichen Gentilnomen Aurelius mit Sicherheit die Regierungszeit Caracallas als frühestmögliche Entstehungszeit. ${ }^{64}$

Der zweite Sarkophag mit der Darstellung eines Soldaten aus Aquincum $(A b b .5 a-b)^{65}$ stellt diesen seiner Frau gegenüber, die im linken Seitenfeld wiedergegeben ist. Sie trägt eine lange Tunika und darüber eine palla, hält in der rechten Hand einen Granatapfel und in der linken einen Fruchtkorb. Der bärtige Soldat trägt die kurze, langärmelige Tunika (tunica manicata), die mit dem Ringschnallencingulum gegürtet ist, und das auf der rechten Schulter gefibelte sagum; in der linken Hand hält der Soldat eine Schriftrolle (volumen), in der rechten die Standarte (signum) mit einem Löwenkopf. Aufgrund der antiquarischen Details kann dieser Sarkophag mit dem signifer wieder in die Zeit ab Caracalla datiert werden. ${ }^{66}$

${ }^{52}$ PochMARSKi 1988, 199.

${ }^{53}$ Pochmarski 1988, 200, Nr. 1, 2, 12; Pochmarski 2001, Nr. 2, 3, 4.

${ }^{54}$ Pochmarski 1988, 200, Nr. 31, 32, 35, 37, 38, 41, 42, 43, 60, 61, 62, 63; PochmaRski 2001, Nr. 5, 6, 7, 8, 9, 10, 11, 12, 13 , $14,15,16$.

${ }^{55}$ Pochmarski 1988, Nr. 5, 6, 8, 13-18 (17 auszuscheiden); Liste: Nr. 4, 5, 6, 7, 8, 10, 11, 12.

${ }^{56}$ Pochmarski 1988, Nr. 46-52, 73; Liste: Nr. 9 (neu; $A b b$. 2), 13, 14, 15, 16, 17, 18, 19, 20.

${ }^{57}$ UBL 1969 (2013), 228-239 (Ringschnallencingulum), 517-534 (tunica manicata), 554-570 (sagum), 590-598 (braccae); zum sagum vgl. POCHMARSKi 2004, 571-578.
${ }^{58}$ UBL 1969, 517-518, 560-561, 590.

${ }^{59}$ PoChMARSKi 2001, 202-203, 206-207, Nr. 18-20.

${ }^{60}$ Liste: Nr. 21, 22.

${ }^{61}$ Aquincum-Museum, Inv. 64.10.31; Liste: Nr. 21 (Abb. 3).

${ }^{62}$ Vgl. Kranz 1986, 212-216, 224-227; Goette 1990, 57-59; vgl. POCHMARSKi 1997, 210-211.

${ }^{63}$ Vgl. Brein 1973, 2-3.

64 Ähnlich schlägt M. Németh, Lupa Nr. 2896 eine Datierung in die severische Zeit (212-230 n. Chr.) vor.

${ }^{65}$ Aquincum-Museum, Inv. 66.11.53; Liste: Nr. 22 (Abb. 4).

${ }^{66}$ HARL, Lupa, Nr. 2910 gibt einen wohl zu weiten Datierungsvorschlag in die Zeit von 200 (zu früh) - $260 \mathrm{n}$. Chr. 


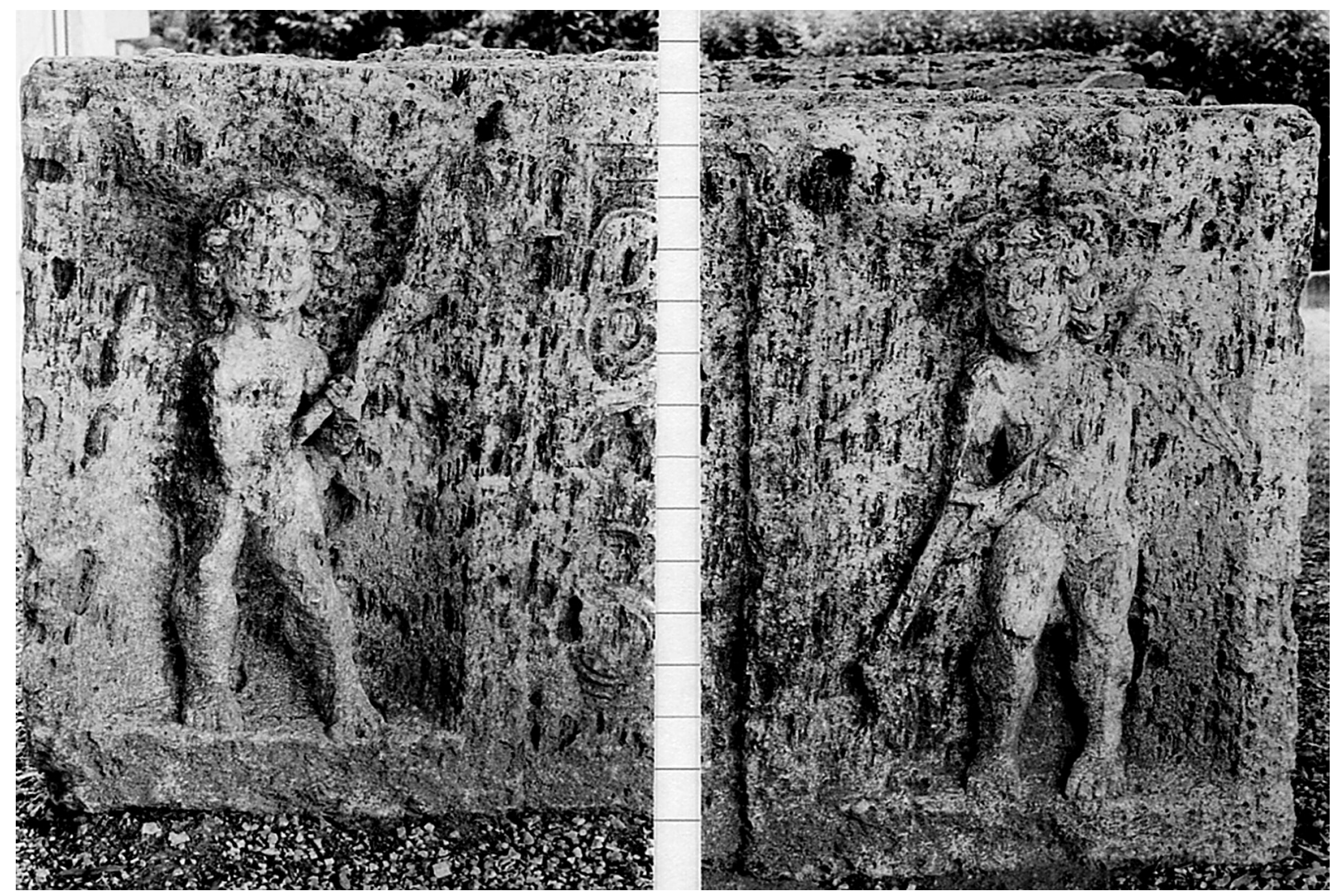

Abb. 1. Sarkophag, Budapest, Aquincum-Museum 86.11.9 (Details: 1. und r. Seitenfläche): Aufnahme O. Harl

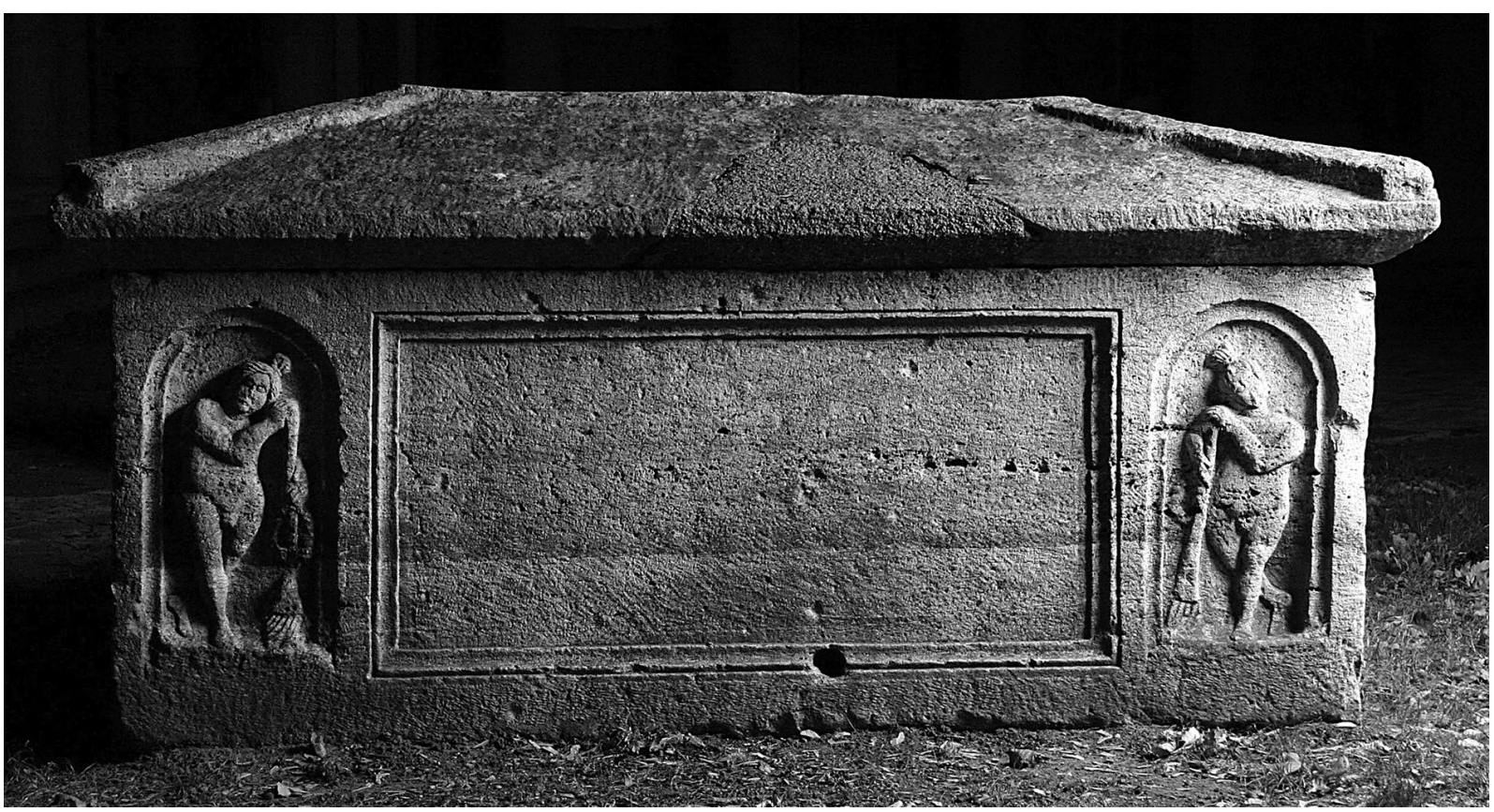

Abb. 2. Sarkophag, Budapest, Aquincum-Museum 66.11.69: Aufnahme O. Harl 

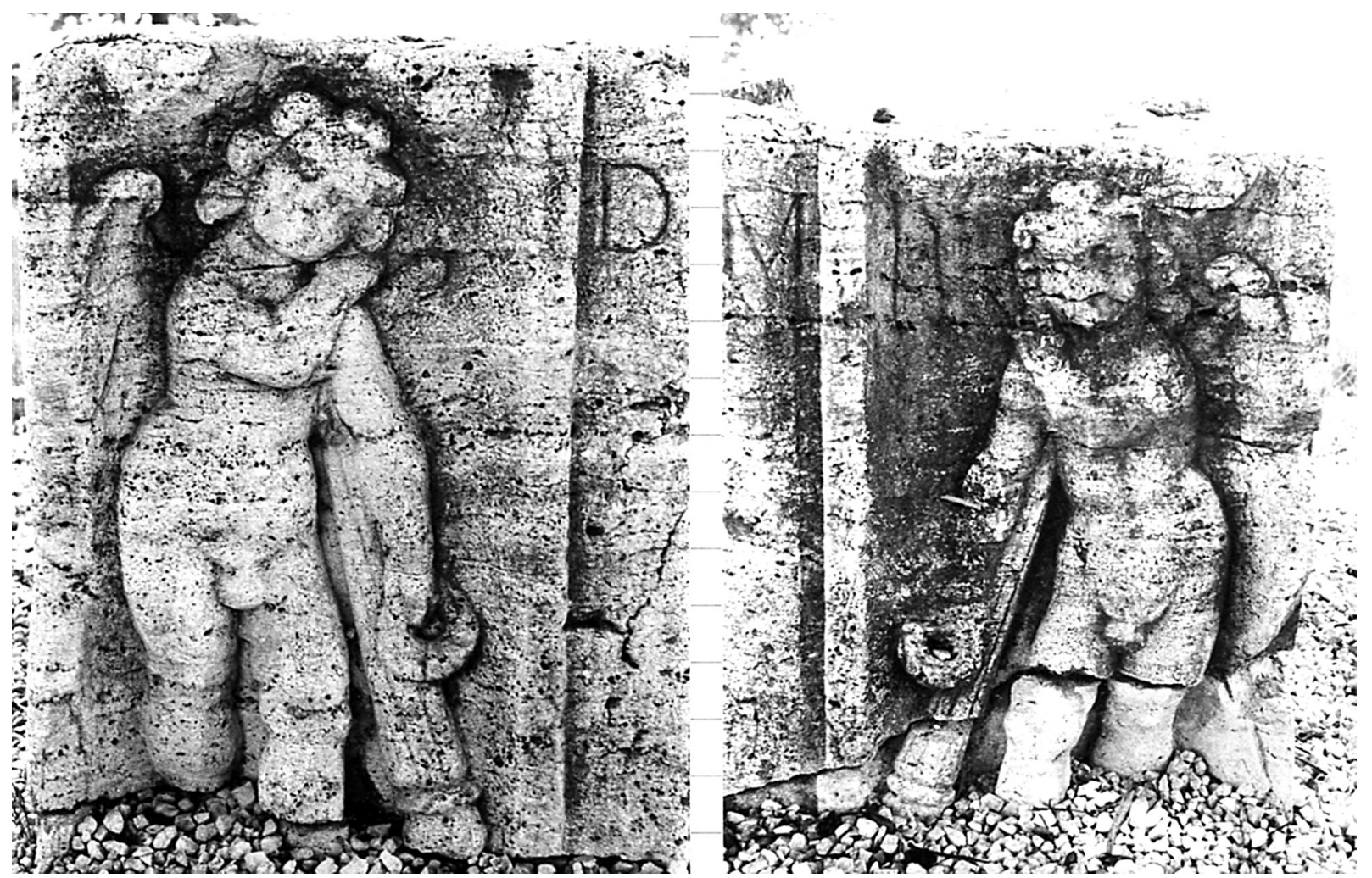

Abb. 3. Sarkophag, Budapest, Aquincum-Museum 64.10.37 (Details: 1. und r. Seitenfläche): Aufnahme Verf.

Die nächste thematische Gruppe stellen Sarkophage mit Privatpersonen dar. Davon hat sich allerdings in Brigetio kein einziges Stück gefunden; in Aquincum handelt es sich immerhin um vier Exemplare ${ }^{67}$ Ein gut erhaltener Sarkophag $(A b b .6)^{68}$ enthält in den Seitenfeldern des vom norisch-pannonischen Volutenornament gerahmten, leer gebliebenen Inschriftfeldes die Darstellungen eines Ehepaares: In dem linken Seitenfeld steht die Frau in Tunika und palla, die in den Händen einen Fruchtkorb hält; in dem rechten ein Togatus mit toga contabulata, der in der Linken die Schriftrolle (volumen) hält, auf die er Zeige- und Mittelfinger der rechten Hand legt bzw. mit ihnen auf sie hinweist. Aufgrund des voll contabulierten umbo handelt es sich um einen Togatypus, der auf die Vorform der toga contabulata folg ${ }^{69}$ und ab der spätseverischen Zeit anzusetzen ist. ${ }^{70}$

Es folgt eine Gruppe von Sarkophagen, die in den Seitenfeldern Männer in orientalischer Tracht zeigen, zu der die phrygische Mütze, eng anliegende Hosen, eine untergegürtete knielange Tunika und mehrfach auch ein Pedum gehören. Die ältere Forschung wollte in diesen Figuren wegen des Trauergestus des geneigten Kopfes, der orientalischen Tracht, des Pedums und der gekreuzten Beine Attis sehen. Erst in jüngerer Zeit haben G. Bauchhenß und N. Cambi auf das Problem der Verdoppelung der Figuren von Attis hingewiesen und in ihnen eher trauernde gefangene Orientalen bzw. Hirten in orientalischer Tracht gesehen. ${ }^{71}$ In ähnlicher Weise wurden von D. Dexheimer die sog. Attisfiguren auf oberitalischen Altären als gefangene Barbaren gedeutet. ${ }^{72}$

Derartige Figuren von Orientalen sind aus Brigetio nur durch einen Sarkophag überliefert, ${ }^{73}$ aus Aquincum aber durch drei. ${ }^{74} \mathrm{Im}$ Fall eines relativ gut erhaltenen Sarkophags ${ }^{75}$ wird das zweifach profilierte Inschriftfeld seitlich von dem sog. norisch-pannonischen Volutenornament gerahmt; in den Seitenfeldern stehen unter den nicht ausgeführten Volutenbögen die beiden Orientalen einander zugewendet gegenüber. Der von G. Bauchhenß und D. Dex-

\footnotetext{
${ }^{67}$ Liste: Nr. $23-26$.

${ }^{68}$ Aquincum-Museum, Inv. 69.1.1; Liste: Nr. 24 (Abb. 6).

${ }^{69}$ Goette 1990, 59-60.

${ }^{70}$ Wieder setzt der Datierungsvorschlag von HARL, Lupa, Nr. 2913 (200-240 n. Chr.) zu früh an und reicht nicht weit genug herab.
}

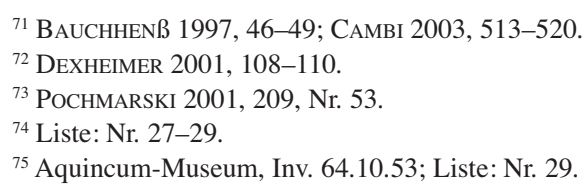



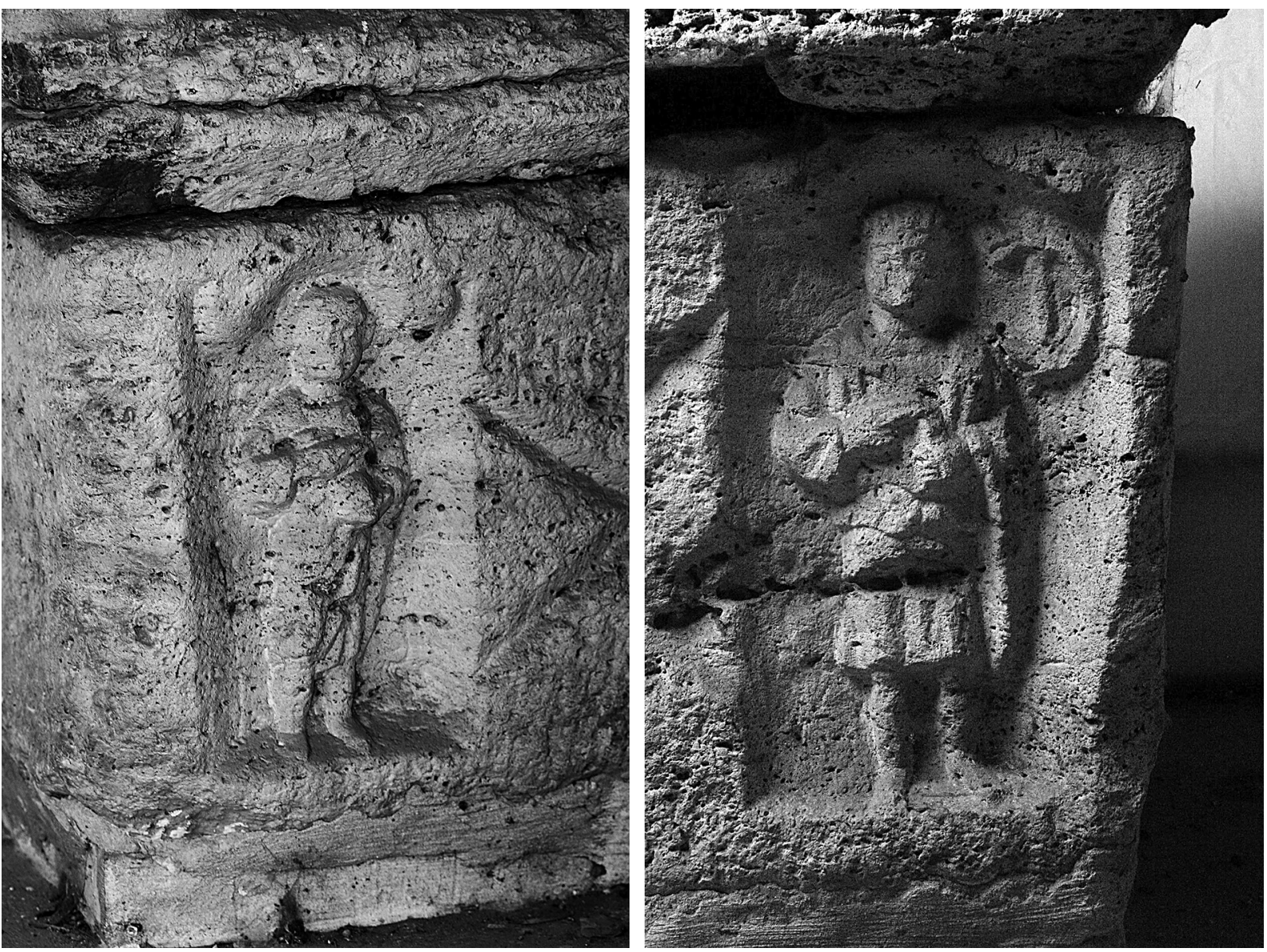

Abb. 4. Sarkophag, Budapest, Aquincum-Museum 64.10.31 (Details: 1. und r. Seitenfläche): AufnahmeO. Harl

heimer angedachte Bezug der Darstellungen auf Bestattungen von Soldaten lässt sich anhand der Inschrift auf diesem Sarkophag nicht verifizieren. Vielmehr handelt es sich bei dem Stifter um einen decurio von Mogentiana, das seit Hadrian municipium war, ${ }^{76}$ was keinen Anhaltspunkt für die Datierung gibt, wohl aber den Beweis, dass es sich um einen Zivilisten gehandelt hat. Im Falle eines zweiten Sarkophags ${ }^{77}$ fehlt eine Inschrift und nur in einem Fall $^{78}$ ist als Stifter ein centurio der legio II adiutrix genannt.

Die nächste Gruppe bilden Sarkophage, bei denen die tabula seitlich von dem sog. norisch-pannonischen Volutenornament als einzigem plastischem Schmuck gerahmt wird (Abb. 7). Mit dessen zeitlicher Ansetzung hat sich P. Kranz mehrfach befasst. ${ }^{79}$ Die von ihm vertretene Ansicht, dass sich ein sicherer Datierungsansatz für das norischpannonische Volutenornament erstmals in dem seitlichen Abschluss einer Votivinschrift des C. Iulius Severus aus Aquincum finde, die auf $201 \mathrm{n}$. Chr. zu datieren ist, ${ }^{80}$ wird zwar durch den oberen Abschluss des gleichfalls aus Aquincum stammenden, auf $164 \mathrm{n}$. Chr. datierten Weihaltars des L. Aelius Celsus ${ }^{81}$ relativiert, besitzt aber unter Umständen für den seitlichen Abschluss der tabula weiterhin Gültigkeit. Für Brigetio konnten vom Verfasser 15 Sarkophage zusammengestellt werden, die das norisch-pannonische Volutenornament als einzigen bildhauerischen Dekor tragen. ${ }^{82}$ Hinzu kommen noch weitere sechs Sarkophage, die außer dem norisch-pannonischen Volutenornament auch

${ }^{76}$ Mócsy 1962, 599.

77 Aquincum-Museum, Inv. ?; Liste: Nr. 28

${ }^{78}$ MNM, Inv. 19.1968.1; Liste: Nr. 27.

${ }^{79}$ KRANZ 1984b, 164-170; KranZ 1986, 211-212; vgl. Pochmarski-NAgele 1992, 166-168.

${ }^{80} \mathrm{Vgl}$. NAGY 1963, 377, Taf. 87.3.
${ }^{81}$ Vgl. POCHMARSKi 1998, 195-196.

82 Pochmarski 2001, 207-208, Nr. 23-36. Die Zahl der Sarkophage lässt sich vielleicht durch ein weiteres Stück auf 16 erhöhen: BARKÓCZI-SOPRONI 1981, 108-109, Nr. 740, Abb. 77. 

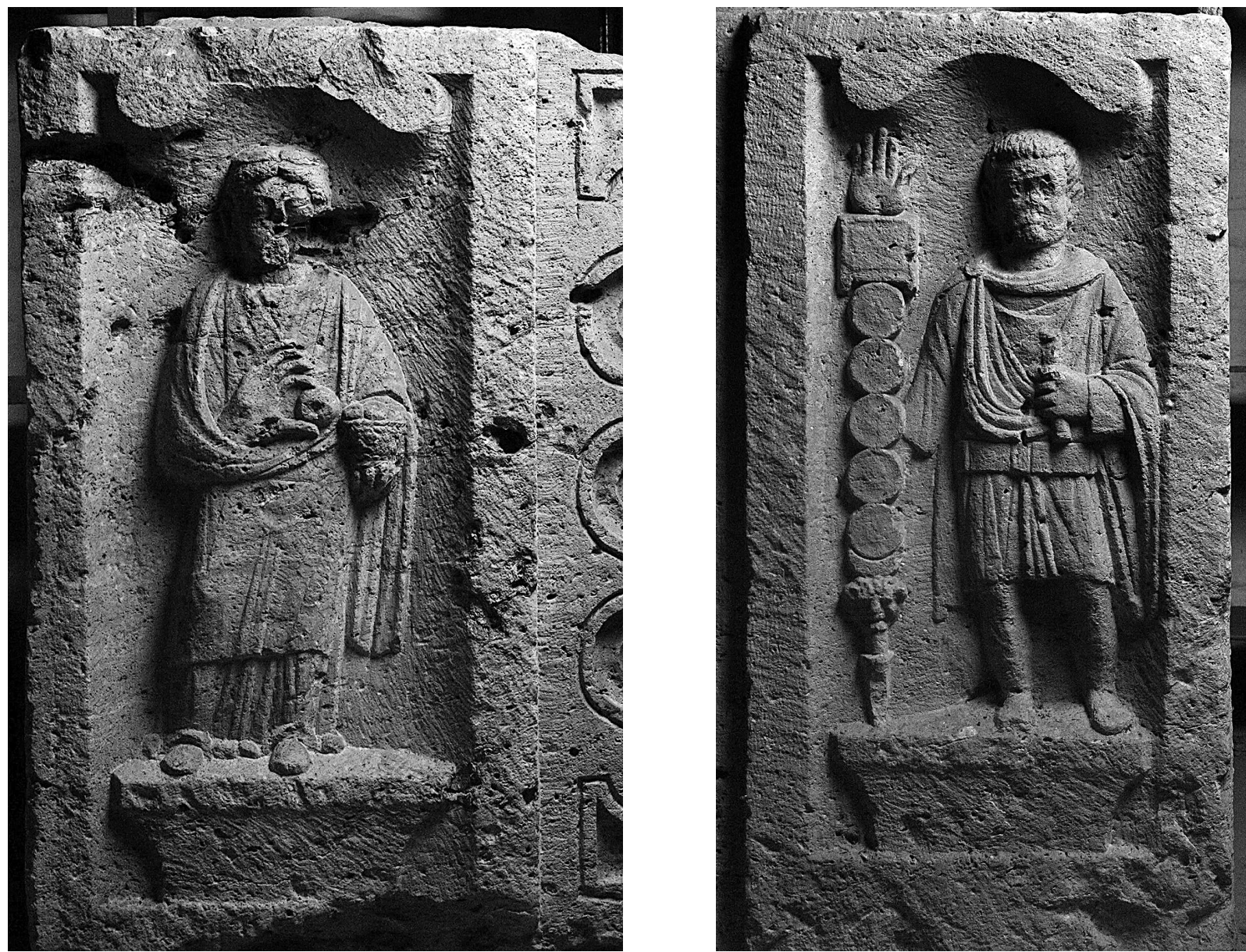

Abb. 5. Sarkophag, Budapest, Aquincum-Museum 66.11 .53 (Details: 1. und r. Seitenfläche): Aufnahme O. Harl

zusätzlichen Reliefschmuck haben. ${ }^{83}$ Mithilfe der Kombination des norisch-pannonischen Volutenornaments mit Graberoten, Soldatendarstellungen, dionysischen Figuren, vor allem aber den Inschriften mit Kaisergentilizien ergibt sich, abgesehen von wenigen Ausnahmen, ${ }^{84}$ eine Datierung in die Zeit ab Caracalla.

Für Aquincum lassen sich 24 Sarkophage zusammenstellen, die das sog. norisch-pannonische Volutenornament $(A b b .7)^{85}$ als einzigen bildhauerischen Schmuck beiderseits der Tabularänder tragen. ${ }^{86}$ Hinzu kommen elf weitere Sarkophage, ${ }^{87}$ die zusätzlichen bildhauerischen Schmuck tragen. Dabei handelt es sich im Regelfall um Graberoten, ${ }^{88}$ aber auch Darstellungen von Ehepaaren, ${ }^{89}$ von Frauen ${ }^{90}$ und von Orientalen (sog. Attisfiguren), ${ }^{91}$ von denen bereits die Rede war. Von den 24 Sarkophagen, die nur mit dem sog. norisch-pannonischen Volutenornament dekoriert sind, ergibt sich in acht Fällen ${ }^{92}$ aus der Angabe des Gentilnomen Aurelius bzw. Aurelia mit großer Wahrscheinlichkeit ein zeitlicher Ansatz ab Caracalla. Andere Kaisergentilizien wie Septimia ${ }^{93}$ oder Iulii ${ }^{94}$ weisen an das Ende des 2. Jahrhunderts n. Chr. ${ }^{95}$ Nur einmal wird die colonia Aquincum genannt, was eine Ansetzung ab Septi-

${ }^{83}$ Pochmarski 2001, Nr. 2, 7, 9, 16, 18, 21.

${ }^{84}$ Pochmarski 2001, Nr. 23, 28, 36: ab Marc Aurel; Nr. 2, 7, 16: ab Septimius Severus

${ }^{85}$ Z. B. Aquincum-Museum, Inv. 87.4.3; Liste: Nr. 41 (Abb. 6).

${ }^{86}$ Liste: Nr. $30-53$.

${ }^{87}$ Liste: Nr. 1, 6 (Abb. 1), 8, 10, 15, 19, 22 (Abb. 5), 24, 25, 26, 29, 30-41 (Abb. 7), 42-53.

${ }^{88}$ Liste: Nr. 1, 6 (Abb. 1), 8, 10, 15, 19.

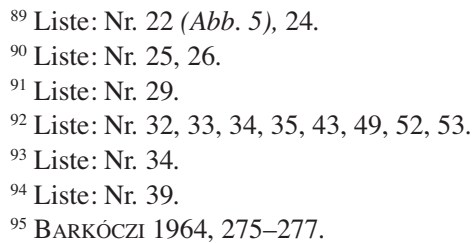




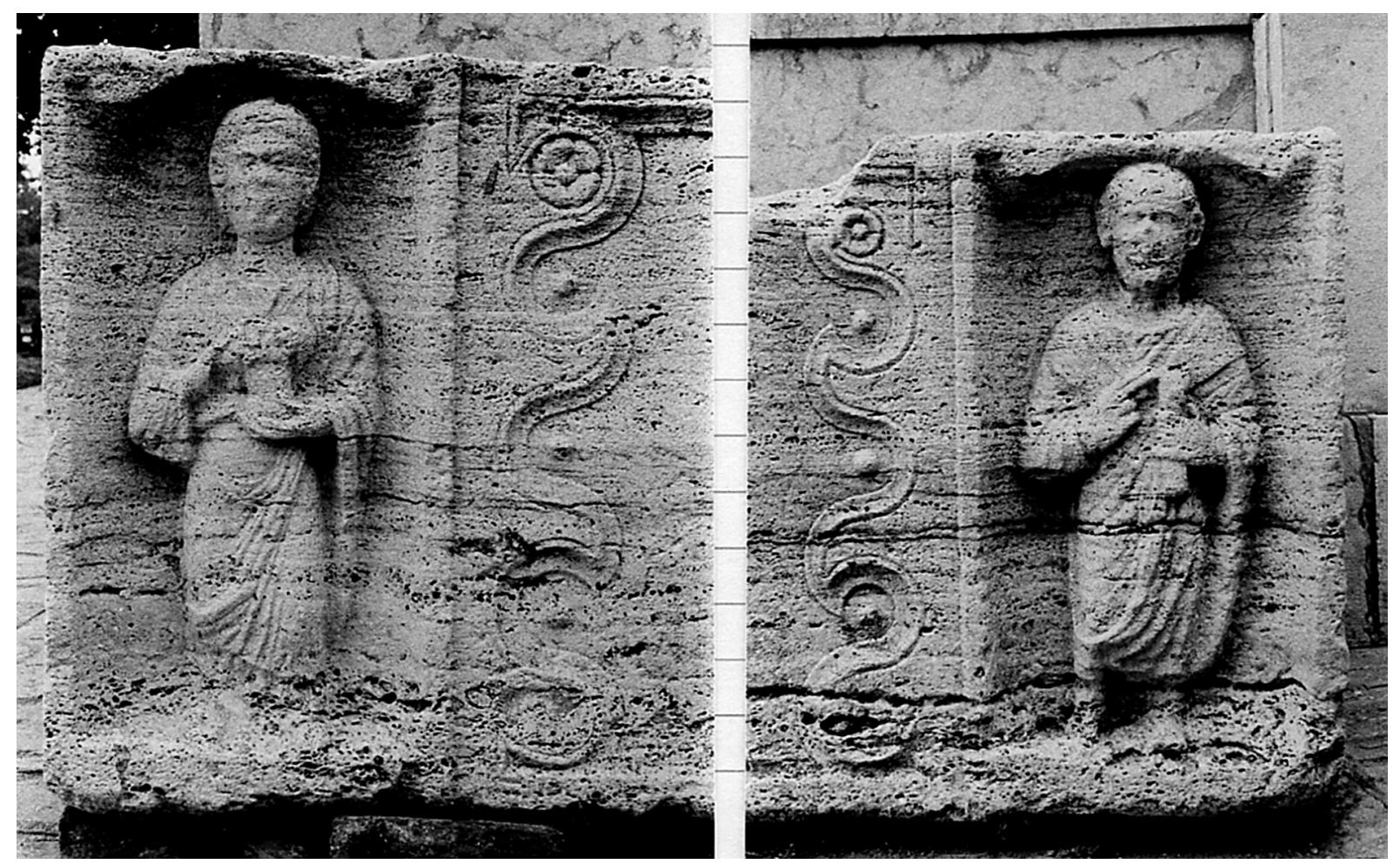

Abb. 6. Sarkophag, Budapest, Aquincum-Museum 69.1.1 (Details: 1. und r. Seitenfläche): Aufnahme Verf.

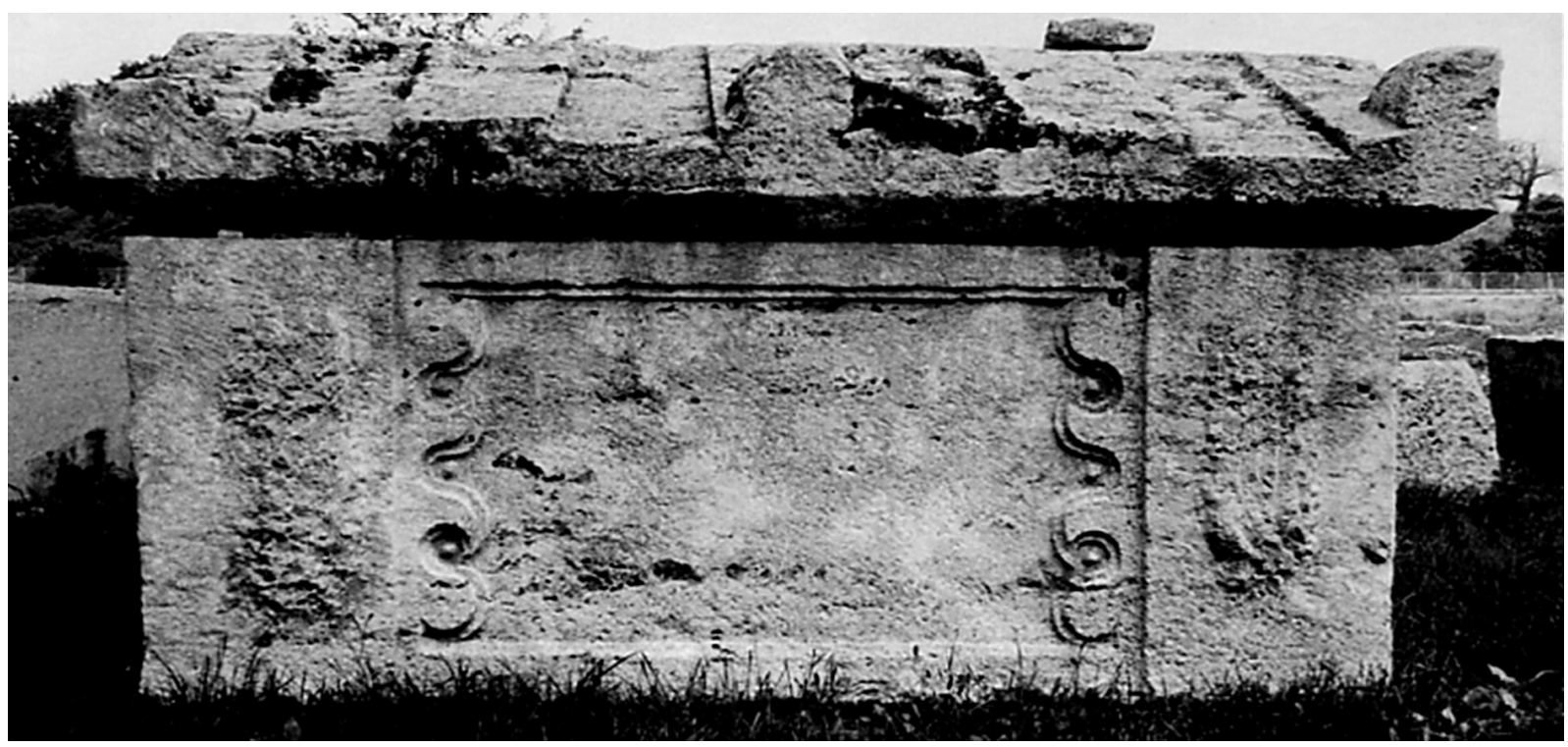

Abb. 7. Sarkophag, Budapest, Aquincum-Museum 87.4.3: Aufnahme Verf. 


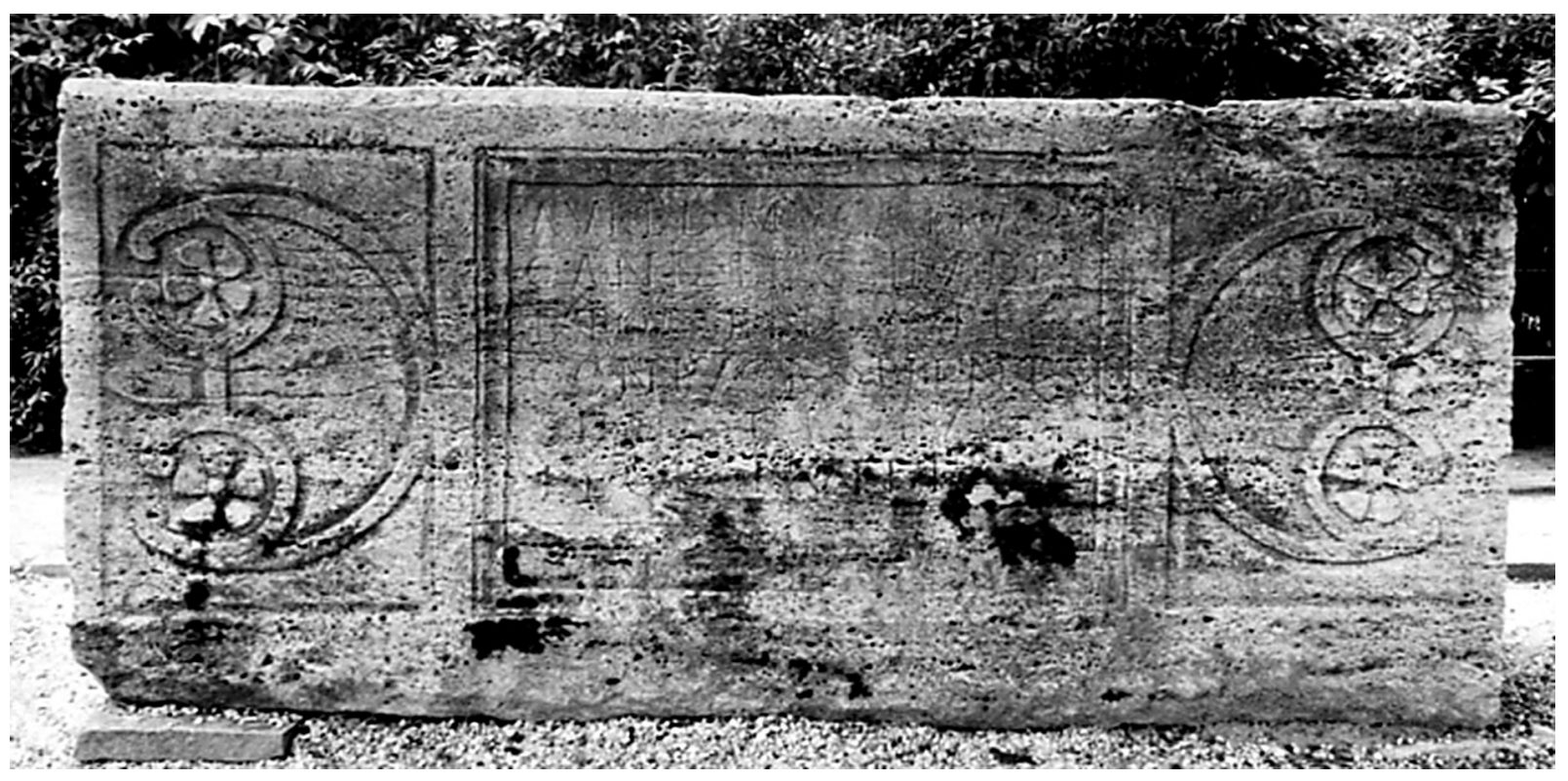

Abb. 8. Sarkophag, Budapest, Aquincum-Museum 72.7.2: Aufnahme Verf.

mius Severus ermöglicht. ${ }^{96}$ In einer Reihe von Inschriften wird die legio II adiutrix genannt, ${ }^{97}$ was jedoch für einen zeitlichen Ansatz nichts hergibt. Allenfalls gibt die Nennung der legio X Fretensis, die während der Markomannenkriege in Aquincum stationiert war, ${ }^{98}$ einen terminus ad quem.

Bis zu einem gewissen Grad lassen sich für Datierungszwecke auch die Darstellungen auf Sarkophagen mit weiterem bildlichem Schmuck außer dem norisch-pannonischen Volutenornament verwerten. Von den Sarkophagen mit Graberoten aus Aquincum lassen sich sechs Exemplare ${ }^{99}(A b b .1)$ den kindlichen Eroten zuordnen und nur einer ${ }^{100}$ den jugendlichen, was bedeutet, dass die Sarkophage mit kindlichen Eroten noch aus der mittelantoninischen-frühseverischen Zeit stammen dürften, während nur der jugendliche Eros mit Sicherheit erst ab der frühseverischen Zeit denkbar ist. Aus den Inschriften dieser Sarkophage lassen sich keine konkreteren Anhaltspunkte gewinnen. Besser sieht es mit den Darstellungen eines Soldaten mit seiner Frau und eines Togatus ebenfalls mit seiner Frau aus, ${ }^{101}$ die sich wegen der Uniform bzw. Togatracht des Mannes sicher erst in die Zeit ab Caracalla datieren lassen.

Bereits bei der Behandlung der Sarkophage von Brigetio hatte sich der Autor mithilfe von M. PochmarskiNagele auch um eine typologische Ordnung der verschiedenen Ausformungen des norisch-pannonischen Volutenornaments bemüht. Dabei wurden von uns ohne chronologische Implikationen die verschiedenen Formen des Ornaments umgezeichnet und als Typen bzw. Varianten bezeichnet. ${ }^{102}$ Für die insgesamt 21 Sarkophage mit norischpannonischen Volutenornament aus Brigetio lassen sich 14 derartige Typen unterscheiden, denen sich jeweils mindestens ein Sarkophag zuweisen lässt. Die Typen reichen von einer Form (Nr. 2), ${ }^{103}$ die an dem eingelegten Pfeil noch den Reflexbogen erkennen lässt, zu Formen mit einer ambossartigen Ausbildung des mittleren Elements, das ursprünglich als Haltegriff des Bogens zu verstehen war, und ausgebildeten Volutenaugen (Nr. 7) $)^{104}$ oder ohne Volutenaugen (Nr. 8). ${ }^{105}$ Das mittlere Element des norisch-pannonischen Volutenornaments kann weiters rund ausgebildet und nach außen (Nr. 3, 4) ${ }^{106}$ oder nach innen gebogen sein $(\mathrm{Nr} .5,6) .{ }^{107}$ Weiters können die Voluten zu zwei stärker gewölbten Halbkreisbögen vereinfacht werden (Nr. 11, 13) ${ }^{108}$ oder zu zwei weniger stark geschwungenen
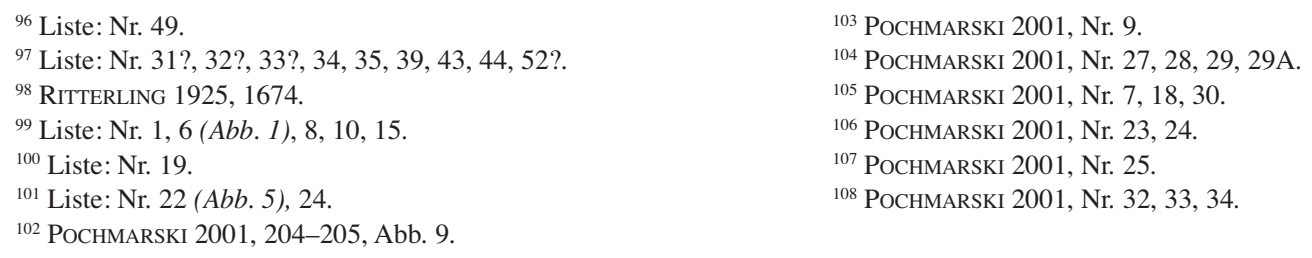


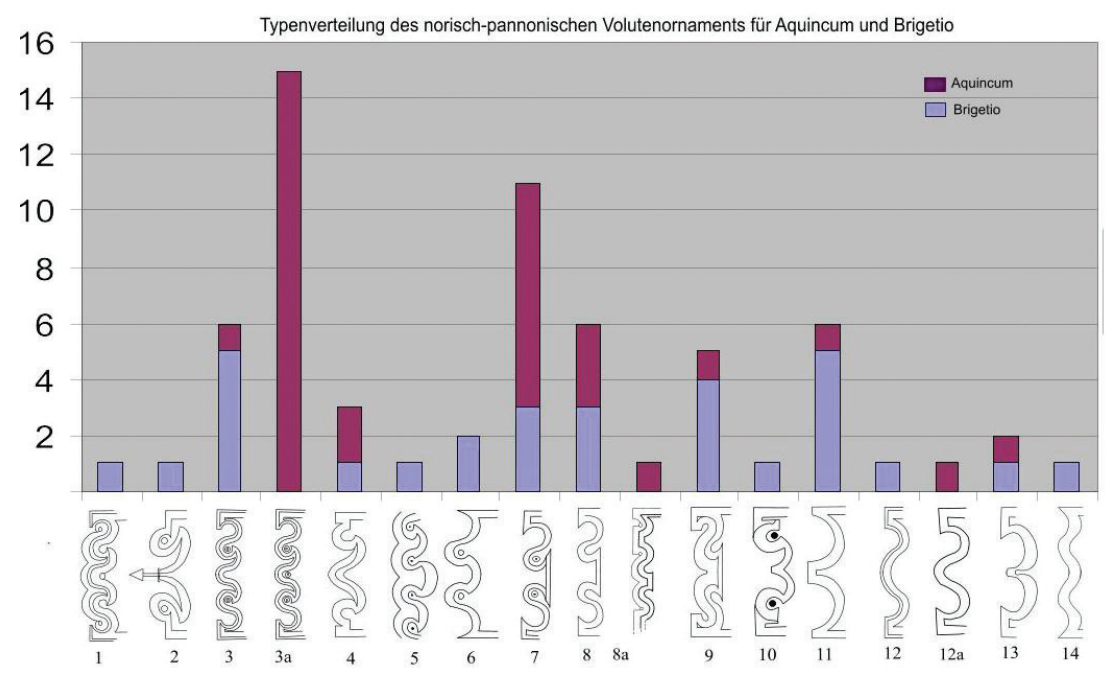

Abb. 9. Norisch-pannonisches Volutenornament auf Sarkophagen aus Brigetio und Aquincum. Graphik: M. Pochmarski-Nagele

Bögen (Nr. 14); ${ }^{109}$ eine Vereinfachung stellt auch der Wellenbogen dar (Nr. 12). ${ }^{110}$ Barocken Reichtum erhält das norisch-pannonische Volutenornament in der Form Nr. 1. ${ }^{111}$ Zusammenfassend betrachtet sind in Brigetio der Typus mit dem nach außen gebogenen Mittelstück (Nr. 3) mit fünf Exemplaren, die Typen mit dem abgeplatteten Mittelteil (Nr. 7-9) mit insgesamt 10 Exemplaren und der zu Halbkreisbögen vereinfachte Typus (Nr. 11) mit fünf Exemplaren am stärksten vertreten.

Ein recht interessantes Ergebnis zeigt der Vergleich mit den in Aquincum vorkommenden Typen des norisch-pannonischen Volutenornaments (Abb. 9). Im Vergleich zu Brigetio fehlen Vertreter des Reflexbogens (Nr. 2), weiters der Formen mit dem nach innen gebogenen Mittelteil (Nr. 5, 6), der hybriden Form Nr. 10 sowie die Vereinfachungen Nr. 13 und 14. Dafür ergibt sich zum Typus Nr. 3 mit nur drei Beispielen eine relativ häufige Variante (Nr. 3a) mit einer dritten Niete in den Volutenaugen mit sechs Beispielen.

Vergleicht man die Verteilung der Typen in Brigetio und Aquincum, so ergibt sich ein recht differenziertes Bild. Der Typus Nr. 3 ist in beiden Städten relativ stark vertreten, der Typus Nr. 3a jedoch nur in Aquincum. Auch der Typus Nr. 4 ist zum Unterschied von Brigetio in Aquincum stark vertreten. Spitzenreiter ist in Aquincum der Typus Nr. 7. Schwächer vertreten ist der Typus Nr. 8 in Aquincum, der in Brigetio ebenfalls durchschnittlich oft vorkommt, während der Typus Nr. 9 in Brigetio öfter vorkommt als in Aquincum und der Typus Nr. 11 in Brigetio zusammen mit dem Typus Nr. 3 am häufigsten vertreten ist, während er in Aquincum kaum vorkommt.

Eine weitere Möglichkeit zur seitlichen Begrenzung des Inschriftfeldes stellen Pelten dar. Während dieser Abschluss aus Brigetio nur ein einziges Mal überliefert ist, ${ }^{112}$ ist er in Aquincum durch elf Sarkophage vertreten $(A b b .8) .{ }^{113}$ Es stellt sich hier die auch für das norisch-pannonische Volutenornament noch nicht befriedigend beantwortete Frage, ob von einer Entwicklung von einfacheren zu komplexeren Formen auszugehen ist. Einfachen Formen ist ein Sarkophag aus Aquincum verpflichtet, ${ }^{114}$ an dem die gegenständigen Pelten ohne jeglichen Innendekor verwendet sind. Die Entwicklung führt wohl in Richtung von reicher dekorierten Pelten, an denen etwa Rosetten in den Peltenbögen auftreten. ${ }^{115}$ Aus den Inschriften dieser Sarkophage aus Aquincum lässt sich nicht sehr viel zur Zeitstellung entnehmen: Zweimal kommt das Gentiliz Aelius ${ }^{116}$ vor, was eine Datierung ab Hadrian möglich macht, ${ }^{117}$ einmal ist von einem Aurelius ${ }^{118}$ die Rede, was wieder eine Datierung ab Caracalla nahe legt. Wohl keine

\footnotetext{
${ }^{109}$ Pochmarski 2001, Nr. 16, 35.

110 Pochmarski 2001, Nr. 22, 36.

111 Pochmarski 2001, Nr. 2.

112 POCHMARSKi 2001, Nr. 37.

${ }^{113}$ Liste: Nr. 54-61 (Abb. 8), 62-64.
}

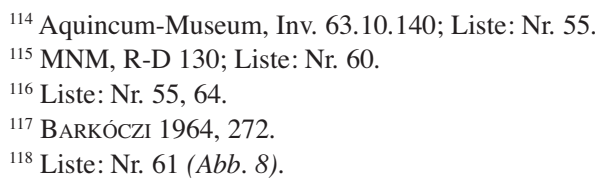

${ }^{114}$ Aquincum-Museum, Inv. 63.10.140; Liste: Nr. 55. 115 MNM, R-D 130; Liste: Nr. 60.

${ }^{116}$ Liste: Nr. 55, 64

117 BARKÓCZI 1964, 272.

${ }^{118}$ Liste: Nr. 61 (Abb. 8) 
Variante des norisch-pannonischen Volutenornaments stellen die selten ${ }^{119}$ als seitlicher Rahmen der tabula vorkommenden Kreis- oder Halbkreisbögen dar.

Zuletzt seien noch die Sarkophage mit der tabula ansata genannt, von denen in Brigetio vier Exemplare erhalten sind, ${ }^{120}$ in Aquincum sechs. ${ }^{121}$ Auch hier lassen sich Sarkophage mit einfachen, nur profilgerahmten ansae von solchen mit Rosetten- oder Blattdekor unterscheiden. Die anhand der Inschriften greifbaren Daten sind spärlich: Einmal ist von Claudii die Rede, ${ }^{122}$ was nach L. Barkóczi eine Datierung ab den Markomannenkriegen erlauben würde, ${ }^{123}$ einmal vom municipium Brigetio, ${ }^{124}$ was eine Datierung zwischen Caracalla und der Mitte des 3. Jahrhunderts n. Chr. ergibt.

Schließlich darf als einfachste Form der plastischen Gestaltung der Sarkophage noch die Profilrahmung der Inschrift angeführt werden: Den neun Exemplaren aus Brigetio ${ }^{125}$ stehen nur sieben aus Aquincum gegenüber. ${ }^{126}$ $\mathrm{Ob}$ sich aus der Art der Profilrahmung - einfach, doppelt, mit Hohlkehle (cyma reversa) - eine Entwicklung ablesen lässt, muss dahingestellt bleiben. Die hier anzutreffenden Inschriften - dreimal das kaiserliche Gentiliz Aurelius ${ }^{127}$ die Nennung der colonia Aquincum ${ }^{128}$ und schließlich in einem Fall die Anführung der legio II adiutrix mit dem Beinamen pia fidelis Antoniniana ${ }^{129}$ - sprechen dafür, dass diese Sarkophage erst in der Zeit ab Caracalla entstanden sein werden.

\section{LISTE DER SARKOPHAGE AUS AQUINCUM}

\section{A. Mythologischer Sarkophag}

1. Sarkophag, Budapest, Magyar Nemzeti Múzeum (Ungarisches Nationalmuseum, in der Folge abgekürzt als MNM) 13.1882.99: CIL III 11066; G. Schön R. v. Weisshäupl, AEM 10, 1886, 116-117, Nr. 3; J. Ziehen, AEM 13, 1890, 54-57; J. Hampel, BudRég 3, 1891 , 64-66, Abb. 4.1-3; Robert 1904, 267, Nr. 215; Ložar 1927, 12, Nr. 38; Koch-Sichtermann 1982, 326, Anm. 45; Pochmarski 1998 191, Nr. 72; Harl, Lupa, Nr. 117.

Vorderseite: Inschriftfeld vom norisch-pannonischen Volutenornament (= NPV) (Typus 9) gerahmt; beiderseits in den Nischen: nackte Figuren, Eroten (Pochmarski 1998, 191, Nr. 72) oder nackte Krieger mit Chlamys und Schwert (Ziehen 1890, 116). L. Nebenseite: Orest und Pylades vor Iphigenie. - R. Nebenseite: Marsyas, Skythe, Apollon.

\section{B. Girlandensarkophag}

2. Sarkophag, Budapest, Aquincum-Museum 64.10.21: Ložar 1927, 6-7, Nr. 19, Abb. 9-11; Paulovics 1927, 66, Abb.; Kuzsinszky 1934, 64-65, Nr. 291, Abb. 23a, b; Nagy 1971, 129-130, Abb. 43, 44; Erdélyi 1974, 65, Anm. 13; 193, Nr. 66, Abb. 66; Mócsy 1974, Taf. 29a; Póczy 1976, Abb. 91; Koch-Sichtermann 1982, 325, Abb. 352; M. Németh, in: L. Borhy-B. Fehér-P. Kovács u. a. 2010, Nr. 681; Harl, Lupa, Nr. 2895.

Vorderseite: Beiderseits des profilierten Inschriftfeldes ein Volutenkrater mit Weinstock; davor eine an Rosetten aufgehängte Blattgirlande, die im Bogen herabhängt bzw. seitlich senkrecht herabfällt. - L. und r. Nebenseite: jeweils ein Tor, eingefasst von Pfeilern, die eine profilierte Archivolte tragen. - Rückseite: an drei Rosetten sind zwei Bögen einer Blattgirlande aufgehängt, die in der Mitte und seitlich senkrecht herabfallen.
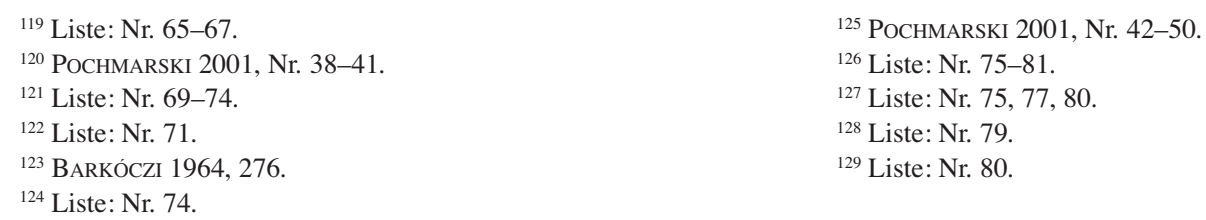


\section{Klinensarkophag}

3. Sarkophag, Budapest, Aquincum-Museum 64.10.66: Kuzsinszky 1934, 190, Nr. 456, Abb. 140; Nagy 1971, 133, 136, Abb. 56; Barkóczi 1982, 19-20, Abb. 2.2; Barkóczi 1982-1983, 124, Taf. 2.5; Koch-Sichtermann 1982, 326, Anm. 53; M. Németh, in: L. Borhy-B. Fehér-P. Kovács u. a. 2010, Nr. 861; Harl, Lupa, Nr. 2891.

Auf einer Kline nach rechts gelagerter Mann mit nacktem Oberkörper; unterhalb der Matratze schmales Inschriftfeld; daneben: Armlehnen in Form eines genius cucullatus.

\section{Sarkophage mit Graberoten in den Seitenfeldern beiderseits des Inschrifteldes}

4. Sarkophagfragment (?), Budapest, Aquincum-Museum 64.10.302: Pochmarski 1998, 183, Nr. 5, Taf. 87.2.

Vorderseite: Inschriftfeld nur zu einem geringen Teil erhalten; im Seitenfeld rechts von der Tabula frontal stehender Eros, Kopf zur Mitte gedreht, Fackel mit beiden Armen erhoben.

5. Sarkophag, Budapest, Aquincum-Museum 64.10.63: Bónis 1945, 561-562, Abb. 571; Németh 1971, 49-50, Nr. 127; Pochmarski 1998, 183, Nr. 6, Taf. 87.3; Németh 1999, 49, Nr. 127; M. Németh, in: P. Kovács-Á. Szabó 2010, Nr. 516; Harl, Lupa, Nr. 2904.

Vorderseite: Tabula ansata; in den Seitenfeldern Eroten (der linke nur sehr bruchstückhaft erhalten), r. Eros: im Kreuzschritt nach außen gehend, Fackeln mit beiden Armen erhoben.

6. Sarkophag, Budapest, Aquincum-Museum 86.11.9 (Abb. 1): Pochmarski 1998, 183, Nr. 8, Taf. 87.5.

Vorderseite: Tabula seitlich vom NPV (Typus 1) gerahmt; in den oben wieder mit dem NPV abgeschlossenen Seitenfeldern Eroten; der 1. Eros nach außen gehend, Fackel mit beiden Armen erhoben gehalten; r. Eros: nach innen gewendet stehend, Fackel mit beiden Armen gesenkt.

7. Sarkophag, Budapest, Aquincum-Museum 86.11.11: Kuzsinszky, BudRég 9, 1906, 67-68, Nr. 33, Abb.; Kuzsinszky 1934, 71, Nr. 265; Pochmarski 1998, 184, Nr. 13; Harl, Lupa, Nr. 2909.

Vorderseite: Beiderseits des einfach gerahmten Inschriftfeldes in den mit dem NPV abgeschlossenen Seitenfeldern Eroten. Beide Eroten stehen zur Mitte gewandt mit überkreuzten Beinen, die Fackel gesenkt und unter die innere Achsel geklemmt, den inneren Arm mit dem Ellbogen auf die Fackel gestützt, den äußeren Arm vor den Körper zur Fackel geführt.

8. Sarkophagfragment, Budapest, Aquincum-Museum 66.11.42: Kuzsinszky, BudRég 5, 1897, 162, Nr. 101, Abb.; Németh 1971, 23, Nr. 43; Pochmarski 1998, 184, Nr. 14, Taf. 87.4; Németh 1999, 23, Nr. 43; Harl, Lupa, Nr. 2765.

Vorderseite: Im Wesentlichen nur das linke Seitenfeld links neben der bis auf einen Rest des NPV weggebrochenen Tabula erhalten; unter dem wieder mit dem NPV abgeschlossenen 1. Seitenfeld steht der Eros nach rechts zur Mitte hin, die Fackel unter die innere Achsel eingestützt, den linken Arm gesenkt, den rechten Arm zur Schulter erhoben.

9. Sarkophag, Budapest, Aquincum-Museum 66.11.69 (Abb. 2): Nagy 1939, 122-125, Abb. 106; Erdélyi 1974, 64, 193, Nr. 64, Abb.; Harl, Lupa, Nr. 2912.

Vorderseite: Profiliert gerahmtes Inschriftfeld; in den profilierten, mit einem Bogen abgeschlossenen Seitenfeldern jeweils ein Eros mit überkreuzten Beinen zur Mitte stehend; der 1. Eros hält mit den beiden Armen die gesenkte Fackel, der r. Eros hat die Fackel unter die rechte Achsel gestützt und hält sie gleichfalls mit beiden Armen.

10. Sarkophag, Budapest, MNM 258.1873.3 (?): CIL III 3544; F. Rómer, Archaeologiai Közlemények 6, 1866, 98 ; Kuzsinszky 1899a, 41, Nr. 26; Ložar 1927, 10, Nr. 30; Pochmarski 1998, 184, Nr. 15, Taf. 87.6; Zs. Mráv, in: P. Kovács-Á. Szabó 2010, Nr. 589; Harl, Lupa, Nr. 3007.

Vorderseite: Profiliertes Inschriftfeld seitlich vom NPV (Typus 7) gerahmt; in den oben gleichfalls mit dem NPV abgeschlossenen Seitenfeldern steht je ein Eros nach innen gewendet, die Fackel gesenkt und unter die innere Achsel gestuitzt, den inneren Arm zur Fackel gesenkt, den äußeren zur gegenüberliegenden Schulter geführt.

11. Sarkophag (?), Budapest, Aquincum-Museum 64.10.65: Parragi 1964, 235, Nr. 17, Abb. 35; Németh 1971, 37, Nr. 84; Pochmarski 1998, 184, Nr. 16; Németh 1999, 38, Nr. 84, Abb.

Vorderseite: Profiliertes Inschriftfeld seitlich von Halbkreisbögen gerahmt; in den Seitenfeldern jeweils ein mit überkreuzten Beinen stehender Eros mit gesenkter Fackel, den inneren Arm zu der unter die Achsel geklemmten Fackel gesenkt, den äußeren auf die gegenüberliegende Schulter gelegt.

12. Sarkophag, Budapest, MNM 0000.142.1 (R-D 142): CIL III 3543; Desjardins-Rómer 1873, 73, Nr. 142, Taf. 24; Ložar 1927, 8, Nr. 25; Pochmarski 1998, 184, Nr. 18; Zs. Mráv, in: P. Kovács-Á. Szabó 2010, Nr. 990; Harl, Lupa, Nr. 3006. 
Vorderseite: In den mit dem NPV abgeschlossenen Seitenfeldern des profilierten Inschriftfeldes steht je ein Eros mit vorgesetztem inneren Spielbein nach innen gewandt; der innere Arm ist wieder zu der unter die Achsel gesteckten gesenkten Fackel geführt, der äußere Arm zur gegenüberliegenden Schulter.

13. Sarkophag, Budapest, Aquincum-Museum 64.10.37 (Abb. 3): CIL III 3560; Rómer 1863, 156, Nr. IX; Pinterović 1978, 152, Taf. 47.3; Pochmarski 1998, 188, Nr. 46, Taf. 88.5.

Vorderseite: Beiderseits des profilierten Inschriftfeldes steht in den mit dem NPV abgeschlossenen Seitenfeldern je ein Eros mit überkreuzten Beinen, den jeweils inneren Arm zu der gesenkten, unter die Achsel gestemmten Fackel gehalten, den jeweils äußeren Arm zu der gegenüberliegenden Schulter geführt.

14. Sarkophag, Budapest, Aquincum-Museum 64.10.38: Nagy 1939, 119-122, Abb. 4, 5; Nagy 1942, 555-556, 574, Taf. 68; Révay 1943, 144-148, Taf. 21.2; Egger 1952, 145-150; AÉpigr 1953, 125; Szilágyi 1963, 189-194; Németh 1971, 65-66, Nr. 183; Erdélyi 1974, 64, 193, Nr. 63, Abb.; Adamik 1976, 203-206; AÉpigr 1977, 634; Soproni, in: Barkóczi-Soproni 1981, 254-255, Nr. 910; Pochmarski 1998, 188, Nr. 47, Taf. 88.6; Németh 1999, 66, Nr. 183; Lörincz 2001, 289, Nr. 451; B. Fehér, in: P. Kovács-Á. Szabó 2010, Nr. 512; Harl, Lupa, Nr. 2908.

Vorderseite: Beiderseits des profilierten Inschriftfeldes (mit metrischer Inschrift) steht in den mit einem NPV abgeschlossenen Seitenfeldern jeweils ein Eros zur Mitte gewandt mit überkreuzten Beinen; die gesenkte Fackel wird mit dem äußeren Arm gehalten, während sich der Ellbogen des inneren Armes auf den Unterarm des anderen Armes stützt und die Hand zum Gesicht geführt ist.

15. Sarkophag, Budapest, Aquincum-Museum 69.1.8: Parragi 1963, 320, Nr. 32, Abb. 22, 23; Pochmarski 1998, 188, Nr. 48, Taf. 89.1. Vorderseite: Inschriftfeld beiderseits vom NPV (Typus 3a) gerahmt. In den beiden Seitenfeldern steht jeweils ein geflügelter Eros mit überkreuzten Beinen; er hat die Fackel gesenkt, hält sie mit dem rechten Arm, der vor den Körper geführt ist, und stützt sich mit dem Ellbogen des linken Armes auf die rechte Hand und die Fackel.

16. Sarkophag, Budapest, MNM R-D 157: CIL III 3527; Desjardins-Rómer 1873, 78-79, Nr. 157, Taf. 26; Fröhlich 1892, 138, Nr. 46; Pochmarski 1998, 188, Nr. 49; M. Németh-E. Tóth, in: P. Kovács-Á. Szabó 2010, Nr. 985; Harl, Lupa, Nr. 2994.

Vorderseite: Das profilierte Inschriftfeld wird beiderseits zunächst von einem stilisierten Baum gerahmt, in der Folge von zwei mit einem Bogen abgeschlossenen Seitenfeldern. In diesen steht mit überkreuzten Beinen je ein Eros, den jeweils inneren Arm zur aufgestützten Fackel gesenkt, den äußeren Arm auf die gegenüberliegende Schulter gelegt.

17. Sarkophag, Budapest, MNM R-D 154: CIL III 10515; Desjardins-Rómer 1873, 77-78, Nr. 154, Taf. 26; Ložar 1927, 9, Nr. 27; Pochmarski 1998, 188, Nr. 50; Zs. Mráv, in P. Kovács-Á. Szabó 2010, Nr. 704; Harl, Lupa, Nr. 3020.

Vorderseite: Das profilierte Inschriftfeld wird von Seitenfeldern gerahmt, die mit dem NPV abgeschlossen sind; in den Seitenfeldern steht je ein geflügelter Eros mit überkreuzten Beinen, den inneren Arm mit der Fackel gesenkt, den äußeren auf die gegenüberliegende Schulter gelegt.

18. Sarkophag, Budapest, MNM 62.97.1-2: CIL III 10533; J. Hampel, AEM 2, 1878, 71, lit. j; Fröhlich 1892, 131, Nr. 35; Ložar 1927, 11, Nr. 35; Pochmarski 1998, 188, Nr. 51; Harl, Lupa, Nr. 7.

Vorderseite: Beiderseits des profilierten Inschriftfeldes steht in den seitlichen Feldern, die mit dem NPV abgeschlossen sind, je ein Eros, die gesenkte Fackel in die jeweils innere Achsel gestützt und den inneren Arm auf die Fackel gelegt, den jeweils äußeren Arm zur gegenüberliegenden Schulter geführt.

19. Sarkophagfragment, Budapest, Aquincum-Museum 64.10.205: B. Kuzsinszky, BudRég 9, 1906, 68-69, Nr. 34, Abb.; Ložar 1927, 5-6, Nr. 17; Pochmarski 1998, 191, Nr. 73.

Rechter unterer Teil der Vorderwand eines Sarkophags; das profilierte Inschriftfeld ist rechts von einem doppelten Kreisbogen (Ložar, Sarkophage 6) oder eher dem nur fragmentarisch erhaltenen NPV gerahmt. Im rechten Seitenfeld sind die Beine eines stehenden Eros mit gesenkter Fackel zu sehen.

20. Sarkophag, ehem. Debrecen, aus Aquincum: Balla 1962, 188-191, Abb. 1; AÉpigr 1964, 9; Pochmarski 1998, 188-189, Nr. 52; Kovács 2005, Nr. 231; Harl, Lupa, Nr. 10123.

\section{E. Sarkophage mit Militärpersonen in den Seitenfeldern beiderseits des Inschrifteldes}

21. Sarkophag, Budapest, Aquincum-Museum 64.10.31 (Abb. 4): CIL III 15160; B. Kuzsinszky, BudRég 7, 1900, 36-38, Nr. 26, Abb. S. 36; Hofmann 1905, 83, Abb. 59; Kuzsinszky 1925, 8-9, Abb. 22; Ložar 1927, 2-3, Nr. 5; Kuzsinszky 1934, 69, Nr. 216, Abb. 25; Nagy 1987-1988, 236-242, Abb. 1; M. Németh, in: P. Kovács-Á. Szabó 2010, Nr. 546; Harl, Lupa, Nr. 2896. 
Vorderseite: Einfach gerahmtes Inschriftfeld mit gravierten ansae; die beiden Seitenfelder sind mit dem NPV abgeschlossen; in dem 1. Seitenfeld steht ein Togatus in der sog. Vorform der toga contabulata; in dem r. Seitenfeld steht ein Legionssoldat, der die kurze, langärmelige Tunika (tunica manicata) trägt, die mit einem Ringschnallencingulum gegürtet ist; darüber ist er mit dem an der rechten Schulter mit einer Scheibenfibel zusammengehaltenen sagum bekleidet; in der linken Hand hält der Soldat eine Rolle (volumen), auf die er die Finger der rechten Hand im Schwur- oder einem deiktischen Gestus legt; über seiner linken Schulter erscheint sein Horn (cornu).

22. Sarkophag, Budapest, Aquincum-Museum 66.11.53 (Abb. 5): Nagy 1945, 537-540, Abb. 1; Póczy 1969, 48, Abb. 39; Nagy 1971, 134, Abb. 59; Póczy 1974, 46, Abb. 39; Erdélyi 1974, 64, 193, Nr. 65, Abb.; Póczy 1976, Abb. 95; Harl, Lupa, Nr. 2910.

Vorderseite: Das profilierte Inschriftfeld ist seitlich vom NPV eingefasst; die beiden Seitenfelder haben als oberen Abschluss gleichfalls das NPV. Im linken Seitenfeld steht die Frau des im rechten Seitenfeld wiedergegebenen Soldaten; sie trägt tunica und palla; im rechten Seitenfeld steht der bärtige Soldat, der die kurze Ärmeltunika (tunica manicata) mit dem Ringschnallencingulum und darüber das sagum trägt; in der linken Hand hält er eine Schriftrolle (volumen), in der rechten Hand die Standarte (signum).

\section{F. Sarkophage mit Zivilpersonen in den Seitenfeldern beiderseits des Inschrifteldes}

23. Sarkophag, Budapest, MNM 31.1869: CIL III 6463: 10391; Desjardins-Rómer 1873, Nr. 211, Taf. 34; Fröhlich 1892, 149, Nr. 74; Ložar 1927, Sarkophage 8-9, Nr. 26; M. Németh-E. Tóth, in: P. Kovács-Á. Szabó 2010, Nr. 777; Harl, Lupa, Nr. 2727.

Vorderseite: Das profilierte Inschriftfeld ist von einem stilisierten Blattornament (Abart des NPV) gerahmt; die beiden Seitenfelder sind oben mit dem NPV abgeschlossen. Im linken Seitenfeld steht eine Frau in tunica und palla (bei Harl, Lupa, Nr. 2727 irrtümlich als Diener bezeichnet), die in den beiden nach rechts gestreckten Armen eine Schale hält. Im rechten Seitenfeld steht eine männliche Figur in der kurzen, untergegürteten Tunika mit Fransentuch (mappa) über der linken Schulter und niedrigen Stiefeln, den rechten Arm mit einem Becher erhoben, den linken Arm gesenkt. Vor ihm steht ein Pfeiler (Altar), auf dem eine Flamme brennt (Harl, Lupa, Nr. 2727: irrtümlich Laterne).

24. Sarkophag, Budapest, Aquincum-Museum 69.1.1 (Abb. 6): B. Kuzsinszky, BudRég 5, 1897, 163, Nr. 103, Abb.; Ložar 1927, 11-12, Nr. 37, Abb. 17,18; Kuzsinszky 1934, Nr. 79; Nagy 1950a, 368, Abb. 7; Póczy 1976, Abb. 87, 88; Harl, Lupa, Nr. 2913.

Vorderseite: Das profilierte Inschriftfeld ist seitlich vom NPV gerahmt; in den mit dem NPV oben abgeschlossenen Seitenfeldern steht im linken eine Frau mit tunica und palla, die in den Händen vor dem Körper einen Fruchtkorb hält. Der Mann im rechten Seitenfeld ist als Togatus mit voll contabulierter toga wiedergegeben; in der linken Hand hält er eine Schriftrolle, auf die er mit Mittelund Zeigefinger der linken Hand hinweist.

25. Sarkophagfragment, Budapest, Aquincum-Museum 64.10.62: Németh 1971, 49, Nr. 125; Németh 1999, 49 , Nr. 125.

Linke obere Hälfte der Vorderwand eines Sarkophags. Das profilierte Inschriftfeld ist links mit dem NPV (Typus 7) abgeschlossen. In dem großteils erhaltenen linken Seitenfeld steht ein Togatus, wobei der umbo der toga noch nicht contabuliert erscheint.

26. Sarkophag, Budapest, Aquincum-Museum 63.10.102: CIL III 14350; B. Kuzsinszky, BudRég 5, 1897, 162, Nr. 102, Abb.; Kuzsinszky 1899b, 69-70, Abb. 32; Ložar 1927, 9, Nr. 28, Abb. 14; Kuzsinszky 1934, 206, Nr. 72; Németh 1971, 51-52, Nr. 135; Németh 1999, 51, Nr. 135, Abb.; M. Németh, in: P. Kovács-Á. Szabó 2010, Nr. 719; Harl, Lupa, Nr. 2905.

Vorderseite: Das profilierte Inschriftfeld wird auf beiden Seiten von einem mit Bogen abgeschlossenen Seitenfeld eingefasst. In den beiden Seitenfeldern sitzt nach außen gewendet je eine weibliche Figur (bei Harl, Lupa, Nr. 2905 ist irrtümlich von Attisfiguren mit hochgestelltem Bein die Rede); die beiden Frauenfiguren sind voll bekleidet und haben den Kopf bedeckt; auf den jeweils äußeren Arm haben sie wohl in einem Trauergestus den Kopf gestützt, der innere Arm liegt im Schoß.

\section{G. Sarkophage mit Orientalen in den Seitenfeldern beiderseits des Inschrifteldes}

27. Sarkophag, Budapest, MNM 19.1968.1: CIL III 3572; Desjardins-Rómer 1873, Nr. 132, Taf. 27; Ložar 1927, 7-8, Nr. 22, Abb. 12; Fitz 1993, 937, Nr. 644; Nagy-Biczó 1998, 81, Abb.; B. Fehér, in: P. Kovács-Á. Szabó 2010, Nr. 745; Harl, Lupa, Nr. 3019.

Vorderseite: Das profilierte Inschriftfeld ist beiderseits von Seitenfeldern gerahmt, die oben mit einer bogenartigen Vorstufe des NPV abgeschlossen sind. In den beiden Seitenfeldern stehen nach innen gewandt mit überkreuzten Beinen zwei Figuren von Orientalen. Sie tragen die phrygische Mütze, eine untergegürtete, knielange, langärmelige Tunika (tunica manicata) und darüber einen über die Schultern geworfenen Mantel sowie eng anliegende Hosen (braccae). Der Kopf ist in einem Trauergestus leicht geneigt, die innere Hand ist zum Kind geführt, die äußere greift vor dem Körper vorbei nach dem aufgestellten Pedum. 
28. Sarkophag, Budapest, Aquincum-Museum, Inv. ?: Nagy 1945, 543-544, Abb. 11, 12 (S. 547).

Vorderseite: Das profilierte Inschriftfeld ist beiderseits vom NPV (Typus 8) gerahmt. In den beiden Seitenfeldern befinden sich einwärts gewendet die Figuren von Orientalen mit phrygischer Mütze, untergegürteter, langärmeliger Tunika (tunica manicata) und engen Hosen (braccae); die beiden Orientalen haben jeweils das innere Bein nach innen zu auf eine Erhebung gesetzt und stehen auf dem äußeren Bein; den inneren Arm haben sie in einem Trauergestus zum Kinn geführt, den äußeren Arm auf das innere Knie gelegt.

29. Sarkophag, Budapest, Aquincum-Museum 64.10.52: CIL III 15166; B. Kuzsinszky, BudRég 7, 1900, 38-40, Nr. 28, Abb. S. 39; Ložar 1927, 11, Nr. 36, Abb. 16; Kuzsinszky 1934, 67-68, Nr. 214, Abb. 24; Mócsy 1974, Taf. 29b; Nagy 1987-1988, 238, Abb. 2.1; M. Németh, in: P. Kovács-Á. Szabó 2010, Nr. 698; Harl, Lupa, Nr. 2899.

Vorderseite: Das profilierte Inschriftfeld ist seitlich von dem NPV eingefasst. In den oben mit dem NPV abgeschlossenen Seitenfeldern steht je eine Orientalengestalt mit überkreuzten Beinen nach innen gewendet da; sie haben jeweils äußeres Standbein und inneres Spielbein; der innere Arm ist in einem Trauergestus zum Kinn geführt, der äußere überkreuzt den Körper und hält das Pedum. Die beiden Orientalen sind wieder mit der phrygischen Mütze, der untergegürteten Ärmeltunika (tunica manicata) und Hosen (braccae) bekleidet.

\section{H. Sarkophage mit dem norisch-pannonischen Volutenornament (NPV) als einzigem Schmuck beiderseits des Inschrifteldes}

30. Sarkophag, Budapest, Aquincum-Museum, Inv. ?.

Vorderseite: Profiliertes Inschriftfeld, das seitlich von dem NPV (Typus 7) gerahmt wird.

31. Sarkophag, Budapest, Aquincum-Museum 63.10.138: CIL III 10501; Bücheler-Lommatzsch 1885-1926, Nr. 489; Nagy 1942, 550; Németh 1971, 65, Nr. 182; Adamik 1978, 184-188; AÉpigr 1979, 470; Póczy 1997, 217; Németh 1999, 64-65, Nr. 182, Abb.; B. Fehér, in: P. Kovács-Á. Szabó 2010, Nr. 519; Harl, Lupa, Nr. 3025.

Vorderseite: Einfach gerahmtes Inschriftfeld (mit metrischer Inschrift); seitlich begrenzt vom NPV (Typus 4?).

32. Sarkophag, Budapest, MNM R-D 133: CIL III 3539; Desjardins-Rómer 1873, 70, Nr. 133, Taf. 23; Zs. Mráv, in: P. Kovács-Á. Szabó 2010, Nr. 287/1-2; Harl, Lupa, Nr. 3005.

Vorderseite: Profiliertes Inschriftfeld, das seitlich vom NPV (Typus 3a) gerahmt wird; Mittelakroter des Sarkophagdeckels: Brustbilder eines Ehepaares mit Kind.

33. Sarkophag, Budapest, MNM 6.1869.2: CIL III 10503; Desjardins-Rómer 1873, Nr. 136, Taf. 27; Zs. Mráv, in: P. Kovács-Á. Szabó 2010, Nr. 527; Harl, Lupa, Nr. 3013.

Vorderseite: Profiliertes Inschriftfeld, seitlich gerahmt vom NPV (Typus 3a).

34. Sarkophag, Budapest, MNM R-D 150: CIL III 3534; Desjardins-Rómer 1873, Nr. 150; Zs. Mráv, in: P. Kovács-Á. Szabó 2010, Nr. 541; Harl, Lupa, Nr. 3003.

Vorderseite: Das einfach gerahmte Inschriftfeld wird beiderseits vom NPV eingerahmt.

35. Sarkophag, Budapest, MNM R-D 141: CIL III 3538; Desjardins-Rómer 1873, Nr. 141, Taf. 23; Ložar 1927, 10, Nr. 33; Zs. Mráv, in: P. Kovács-Á. Szabó 2010, Nr. 539; Harl, Lupa, Nr. 3004.

Vorderseite: Das profilierte Inschriftfeld wird seitlich vom NPV (Typus 4) gerahmt.

36. Sarkophag, Budapest, Aquincum-Museum 64.10.64: T. Nagy, BudRég 13, 1943, 374; Németh 1971, 60, Nr. 163; Németh 1999, 59-60, Nr. 163; M. Németh, in: P. Kovács-Á. Szabó 2010, Nr. 623; Harl, Lupa, Nr. 2964.

Vorderseite: Das profilierte Inschriftfeld wird vom NPV (Typus 7) gerahmt.

37. Sarkophag, Budapest, Aquincum-Museum 86.11.10: unpubliziert.

Vorderseite: Einfach gerahmtes Inschriftfeld vom NPV (Typus 7) gerahmt.

38. Sarkophag, Budapest, Aquincum-Museum 86.11.13: unpubliziert.

Vorderseite: Einfach gerahmtes Inschriftfeld vom NPV gerahmt.

39. Sarkophag, Budapest, Aquincum-Museum 64.10.27: Kuzsinszky 1934, 66, Nr. 288; Soproni 1979, 91-97, Abb. 1.

Vorderseite: Das profilierte Inschriftfeld wird vom NPV (Typus 7) gerahmt.

40. Sarkophag, Budapest, Aquincum-Museum 66.11.62: B. Kuzsinszky, BudRég 5, 1897, 159, Nr. 94.

Vorderseite: Das profilierte Inschriftfeld wird vom NPV gerahmt.

41. Sarkophag, Budapest, Aquincum-Museum 87.4.3 (Abb. 7): Szirmai 1993, 421-427.

Vorderseite: Das profilierte Inschriftfeld wird vom NPV gerahmt.

42. Sarkophag, Budapest, Aquincum-Museum 87.4.4: unpubliziert. 
Vorderseite: Das profilierte Inschriftfeld wird vom NPV gerahmt.

43. Sarkophagfragment, Budapest, Aquincum-Museum 63.10.99: CIL III 3540 + add. P. 2183; B. Kuzsinszky, BudRég 5, 1897, 161 , Nr. 100, Abb.; Ložar 1927, 10, Nr. 31; Németh 1971, 52, Nr. 136; Németh 1999, 51, Nr. 136; M. Németh, in: P. Kovács-Á. Szabó 2010, Nr. 564; Harl, Lupa, Nr. 2911.

Linke Hälfte einer Sarkophagvorderwand. Das profilierte Inschriftfeld war ursprünglich beiderseits vom NPV (Typus 7) gerahmt.

44. Sarkophagfragment, Budapest, Aquincum-Museum 63.10.105: Nagy 1950a, 366-367, Abb. S. 366; Szilágyi 1965, 185-186, Nr. 5, Abb. 9, 10; AÉpigr 1965, 47; AÉpigr 1967, 371; Alföldy 1967, 58, Nr. 5; J. Fitz, Alba Regia 8-9, 1967-1968, 292; AÉpigr 1969-1970, 480; Németh 1971, 49, Nr. 126; Németh 1999, 49, Nr. 126, Abb.; M. Németh, in: P. Kovács-Á. Szabó 2010, Nr. 756; Harl, Lupa, Nr. 2748.

Rechte Hälfte einer Sarkophagvorderwand. Das profilierte Inschriftfeld war ursprünglich beiderseits vom NPV (Typus 4) gerahmt.

45. Sarkophagfragment, Budapest, Aquincum-Museum 75.7.2: Pető 1976, 216, Nr. 4, Abb. 227.

Linke Hälfte einer Sarkophagvorderwand. Das profilierte Inschriftfeld ist auf der linken Schmalseite vom NPV (Typus 3) gerahmt.

46. Sarkophag, Budapest, Aquincum-Museum 66.11.52: Nagy 1971, 134, Abb. 60 (S. 138); Harl, Lupa, Nr. 2921.

Vorderseite: Das profilierte Inschriftfeld ist beiderseits vom NPV (Typus 1) gerahmt.

47. Sarkophag, Budapest, Aquincum-Museum 66.11.58: unpubliziert.

Vorderseite: Profiliertes Inschriftfeld vom NPV (Typus 1) gerahmt.

48. Sarkophag, Budapest, Aquincum-Museum 66.11.55: B. Kuzsinszky, BudRég 5, 1897, 159-160, Nr. 97.

Vorderseite: Profiliertes Inschriftfeld vom NPV (Typus 7) gerahmt.

49. Sarkophagfragment, Budapest, Aquincum-Museum 63.10.37: CIL III 3533 = 13367; Fröhlich 1892, 139-140, Nr. 49; B. Kuzsinszky, BudRég 5, 1897, 160-161, Nr. 99; Kuzsinszky 1934, 183, Nr. 41; M. Németh, in: P. Kovács-Á. Szabó 2010, Nr. 559; Harl, Lupa, Nr. 4983.

Linke Hälfte einer Sarkophagvorderwand. Profiliertes Inschriftfeld seitlich vom NPV gerahmt.

50. Sarkophag, Budapest, Aquincum-Museum 64.10.50: Kuzsinszky 1934, 66, Nr. 281; Nagy 1971, 234, Abb. 61 (S. 138); M. Németh, in: P. Kovács-Á. Szabó 2010, Nr. 638; Harl, Lupa, Nr. 2894.

Vorderseite: Das profilierte Inschriftfeld ist an den Schmalseiten beiderseits vom NPV (Typus 11) gerahmt.

51. Sarkophag, Budapest, Aquincum-Museum, Inv. ?: unpubliziert.

Vorderseite: Das einfach gerahmte Inschriftfeld ist vom NPV (Typus 13) eingefasst.

52. Sarkophag, Budapest, MNM 48.1882.2: CIL III 10505; Zs. Mráv, in: P. Kovács-Á. Szabó 2010, Nr. 547; Harl, Lupa, Nr. 3034. Vorderseite: Profiliertes Inschriftfeld vom NPV gerahmt.

53. Sarkophag, Budapest, Aquincum-Museum 81.7.9: B. Fehér-M. Németh, in: P. Kovács-Á. Szabó 2010, Nr. 563; Harl, Lupa, Nr. 4457. Vorderseite: Das profilierte Inschriftfeld wird vom NPV gerahmt.

\section{Sarkophage mit Peltenornament als einzigem Schmuck beiderseits des Inschrifteldes}

54. Sarkophag, Budapest, Aquincum-Museum, Inv. ?: Nagy 1945, 541, Nr. III-IV, Abb. 5 (S. 542 ).

Vorderseite: Beiderseits des profilierten Inschriftfeldes finden sich Pelten mit einer Spitze zwischen den beiden Ausnehmungen.

55. Sarkophag, Budapest, Aquincum-Museum 63.10.140: CIL III 14347³; B. Kuzsinszky, BudRég 7, 1900, 40-41, Nr. 30, Abb.; Ložar 1927, 3, Nr. 7; Kuzsinszky 1934, 71, Nr. 183; M. Németh, in: P. Kovács-Á. Szabó 2010, Nr. 502; Harl, Lupa, Nr. 2901.

Vorderseite: Profiliert gerahmtes Inschriftfeld seitlich von einfachen Pelten eingefasst.

56. Sarkophag, Budapest, Aquincum-Museum 66.11.63: B. Kuzsinszky, BudRég 5, 1897, 159, Nr. 95, Abb.; Ložar 1927, 4, Nr. 9. Vorderseite: Das einfach gerahmte Inschriftfeld ist an den Schmalseiten von einfachen Pelten eingefasst.

57. Sarkophagfragment, Budapest, Aquincum-Museum 64.1172: unpubliziert.

Rechte Hälfte einer Sarkophagvorderwand. Das einfach gerahmte Inschriftfeld ist rechts von einer Pelte mit kleineren Ausnehmungen und längerem Verbindungssteg dazwischen eingefasst.

58. Sarkophag, Budapest, Aquincum-Museum 66.11.59: B. Kuzsinszky, BudRég 5, 1897, 159, Nr. 94; B. Kuzsinszky, BudRég 7, 1900, 43-44, Nr. 33; Nagy 1928, 74, Nr. 14, Abb. 27; T. Nagy, BudRég 15, 1950, 171, Nr. 57; Harl, Lupa, Nr. 2965.

Vorderseite: Das einfach gerahmte Inschriftfeld ist beiderseits von Pelten eingefasst, deren Enden sich leicht einrollen.

59. Sarkophag, Budapest, Aquincum-Museum 66.11.56: unpubliziert.

Vorderseite: Das einfach gerahmte Inschriftfeld ist beiderseits von Pelten eingefasst, deren Enden sich volutenförmig einrollen. 
60. Sarkophag, Budapest, MNM R-D 130: CIL III 3557; Desjardins-Rómer 1873, 69-70, Nr. 130, Taf. 22; Hampel 1907, 336, Abb. 53; Zingerle 1922-1924, 243, Abb. 83; Ložar 1927, 4, Nr. 12; Erdélyi 1974, 63, Abb. 61; Fitz 1994, 1139, Nr. 791; Zs. Mráv, in: P. Kovács-Á. Szabó 2010, Nr. 991; Harl, Lupa, Nr. 3009.

Vorderseite: Das profilierte Inschriftfeld ist auf beiden Schmalseiten von Pelten mit eingerollten Enden eingefasst; in den Ausnehmungen der Pelten befinden sich vierblättrige Rosetten; zwischen den Ausnehmungen ist eine Spitze zu sehen.

61. Sarkophag, Budapest, Aquincum-Museum 72.7.2 (Abb. 8): M. Németh, in: P. Kovács-Á. Szabó 2010, Nr. 536; Harl, Lupa, Nr. 6652. Profiliertes Inschriftfeld seitlich von Pelten gerahmt; in deren Ausnehmungen befinden sich fünfblättrige Rosetten.

62. Sarkophagfragment, Budapest, Aquincum-Museum 73.9.17: Nagy 1971, 133-134, 136, Abb. 57.

Linke Hälfte einer Sarkophagvorderwand; das profilierte Inschriftfeld ist links von einer Pelte gerahmt, deren Enden eingerollt sind; in den Ausnehmungen befinden sich vierblättrige Rosetten; den Peltenkörper verzieren gegenständige Akanthusblätter; in dem Seitenfeld befinden sich in den inneren Ecken zwei weitere Rosetten.

63. Sarkophagfragment, Budapest, Aquincum-Museum 86.11.15: Szirmai 1985, 223, Abb. 2.

Rechte Hälfte eines Sarkophags; das einfach gerahmte Inschriftfeld wird rechts von einem Seitenfeld mit Pelta eingefasst, deren Ausnehmungen oben und unten jeweils in zwei Voluten enden.

64. Sarkophag, Budapest, MNM: CIL III 10538; Ložar 1927, 4, Nr. 10; P. Kovács-B. Fehér-Á. Szabó, in: P. Kovács-Á. Szabó 2010, Nr. 517/1 und 799/3; Harl, Lupa, Nr. 3044.

Vorderseite: Kindersarkophag mit einfach gerahmtem Inschriftfeld; in den beiden Seitenfeldern Pelten mit doppelt eingerollten Enden und Rosetten in den Ausnehmungen; in den inneren Ecken der Seitenfelder Akanthusblätter.

\section{J. Sarkophage mit Kreisen bzw. Halbkreisen als Schmuck in den Seitenfeldern beiderseits des Inschrifteldes}

65. Sarkophagfragment, Budapest, Aquincum-Museum 86.10.7: unpubliziert.

Rechte Hälfte eines Sarkophagkastens. Rechts von dem profilierten Inschriftfeld das Seitenfeld mit einem profilierten Kreis und kleinem eingeschriebenem, profiliertem Mittelkreis.

66. Sarkophag, Budapest, Aquincum-Museum 64.10.29: CIL III 15165; B. Kuzsinszky, BudRég 7, 1900, 40, Nr. 29; Ložar 1927, 5, Nr. 13; Kuzsinszky 1934, 70, Nr. 215; Nagy 1987-1988, 238, Abb. 2.2; M. Németh, in: P. Kovács-Á. Szabó 2010, Nr. 717; Harl, Lupa, Nr. 2900.

Das profilierte Inschriftfeld wird beiderseits von großen Halbkreisen mit Hohlkehle (cyma reversa) gerahmt.

67. Sarkophag, Budapest, Aquincum-Museum, Inv. ?: unpubliziert.

Vorderseite: Profiliertes Inschriftfeld seitlich von profilierten großen Halbkreisen gerahmt.

\section{K. Sarkophag mit Akanthuskelch beiderseits des Inschriftfeldes}

68. Sarkophag, Budapest, Aquincum-Museum 66.11.70: Ložar 1927, 8, Nr. 24, Abb. 13; Nagy 1950a, 365, Abb. 5.

Vorderseite: Das einfach profilierte Inschriftfeld wird seitlich von einem vertikalen, zweigeteilten Akanthuskelch eingefasst, dessen Blattenden sich einrollen.

\section{Sarkophage mit tabula ansata als seitlicher Rahmung des Inschrifteldes}

69. Sarkophag, Budapest, Aquincum-Museum 66.11.64: unpubliziert.

Vorderseite: Das profilierte Inschriftfeld wird beiderseits von profilierten dreieckigen ansae eingefasst; in den freien Ecken der Seitenfelder befinden sich Blätter.

70. Sarkophag, Budapest, Aquincum-Museum 64.10.51: Nagy 1920-1922, 52, Abb. 12; Ložar 1927, 2, Nr. 3; Kuzsinszky 1934, 66, Nr. 282; Korbuly 1934, 7, Nr. 2, Abb. 1; Nagy 1945, 546-548, Abb. 13; Nagy 1971, 133-134, Abb. 58; Erdélyi 1974, 63, 193, Nr. 62, Abb.; M. Németh, in: P. Kovács-Á. Szabó 2010, Nr. 684; Harl, Lupa, Nr. 2907.

Vorderseite: Das einfach profilierte Inschriftfeld ist beiderseits von profilierten ansae eingefasst; jenseits der ansae findet sich eine aus einem Gefäß wachsende Ranke (Efeuranke). 
71. Sarkophag, Budapest, Aquincum-Museum 72.7.5: Wellner 1971, 411-414, 417-418, Abb. 6-8; AÉpigr 1972, 382; M. Németh, in: P. Kovács-Á. Szabó 2010, Nr. 644; Harl, Lupa, Nr. 5069.

Vorderseite: Das einfach gerahmte Inschriftfeld ist in den Seitenfeldern von einfach gravierten ansae gerahmt.

72. Sarkophag, Budapest, Aquincum-Museum 72.7.4: AÉpigr 2001, 1691; Kovács 2001, 27-28, Nr. 91, 88-101; Kovács et al. 2007, 37 , Nr. 91; B. Fehér, in: P. Kovács-Á. Szabó 2010, Nr. 722; Harl, Lupa, Nr. 294.

Vorderseite: Das einfach gerahmte Inschriftfeld wird von profilierten ansae in den Seitenfeldern eingefasst; in den ansae findet sich eine fünfblättrige Rosette; in den frei bleibenden Zwickeln der Seitenfelder jeweils ein Efeublatt.

73. Sarkophag, Budapest, Aquincum-Museum 91.5.12: unpubliziert.

Vorderseite: Das profilierte Inschriftfeld wird von gleichfalls profilierten ansae eingerahmt; in den ansae befinden sich drei aus einem Knoten wachsende Blätter.

74. Sarkophag, Budapest, MNM 13.1882.96: CIL III 10534; J. Hampel, BudRég 3, 1891, 56, Nr. 59; Ložar 1927, 1-2, Nr. 2, Abb. 5, 6; Barkóczi 1951, Taf. 65.1; Erdélyi 1974, 63, 193, Nr. 61, Abb.; M. Németh-E. Tóth, in: P. Kovács-Á. Szabó 2010, Nr. 619; Harl, Lupa, Nr. 2997.

Vorderseite: Profiliertes Inschriftfeld mit profilierten ansae; in den ansae fünfblättrige Rosetten, umgeben von einer Blattranke.

\section{Sarkophage mit profilierten Inschrifteldern}

75. Sarkophag, Budapest, Aquincum-Museum 64.10.32: CIL III 13374; Kuzsinszky 1899b, 68-69, Nr. 23; B. Kuzsinszky, BudRég 5, 1897, 158-159, Nr. 93; Kuzsinszky 1934, 70, Nr. 58; M. Németh, in: P. Kovács-Á. Szabó 2010, Nr. 750; Harl, Lupa, Nr. 783.

Kindersarkophag mit einfach gerahmter Inschrift und unbearbeiteten Seitenfeldern.

76. Sarkophag, Budapest, Aquincum-Museum 64.10.54: Szilágyi 1955, 355; M. Németh, in P. Kovács-Á. Szabó 2010, Nr. 732; Harl, Lupa, Nr. 5094.

Vorderseite: Dreifach profiliertes Inschriftfeld mit Hohlkehle (cyma reversa) zwischen Graten.

77. Sarkophag, Budapest, Aquincum-Museum 64.10.48: Kuzsinszky 1934, 67, Nr. 433; L. Nagy, BudRég 12, 1937, 268; Szilágyi 1967, 73, Abb. 7; 78, Nr. 4; AÉpigr 1967, 366; Mócsy 1969, 347; AÉpigr 1969-1970, 478; M. Németh, in: P. Kovács-Á. Szabó 2010, Nr. 544; Harl, Lupa, Nr. 2902.

Vorderseite: Zweifach profiliertes Inschriftfeld.

78. Sarkophag, Budapest, Aquincum-Museum 87.4.5: unpubliziert.

Vorderseite: Dreifach profiliertes Inschriftfeld.

79. Sarkophag, Budapest, Aquincum-Museum 64.10.49: Ložar 1927, 6, Nr. 18, Abb. 8; Kuzsinszky 1934, 67, Nr. 382; M. Németh, in: P. Kovács-Á. Szabó 2010, Nr. 624; Harl, Lupa, Nr. 2962.

Vorderseite: Zweifach profiliertes Inschriftfeld.

80. Sarkophag, Budapest, Aquincum-Museum 64.10.28: CIL III 15161; B. Kuzsinszky, BudRég 7, 1900, 38, Nr. 27; Kuzsinszky 1934, 68, Nr. 213; Nagy 1987-1988, 236-237, Abb. 2.2; Fitz 1983, 184; M. Németh, in: P. Kovács-Á. Szabó 2010, Nr. 553; Harl, Lupa. Nr. 2897.

Vorderseite: Dreifach profiliertes Inschriftfeld mit Hohlkehle (cyma reversa).

81. Sarkophag, Budapest, Aquincum-Museum 63.10.139: CIL III 14349; B. Kuzsinszky, BudRég 5, 1897, 166, Nr. 98, Abb.; Kuzsinszky 1934, 72-73, Nr. 78; M. Németh, in: P. Kovács-Á. Szabó 2010, Nr. 586; Harl, Lupa, Nr. 2906.

Vorderseite: Einfach profiliertes Inschriftfeld.

\section{DANKSAGUNG}

Für die Reproduktionserlaubnis der von O. Harl für die Bilddatenbank ubi-erat-lupa.com bzw. vom Autor für das Sarkophag-Corpus der Aufnahmen von O. Harl bin ich J. Beszédes zu großem Dank verpflichtet. 
ADAMIK 1976

ADAMIK 1978

ALFÖLDY 1967

BALLA 1962

BARKÓCZI 1951

BARKÓCZI 1964

BARKÓCZI 1965

BARKÓCZI 1982

BARKÓCZI 1982-1983

BARKÓCZI-MÓCSY 1976

BARKÓCZI-SOPRONI 1981

BAUCHHENß 1997

BÓNIS 1945

BORHY-FEHÉR-KovÁCS et al. 2010

BREIN 1973

BÜCHELER-LOMMATZSCH 1885-1926

BURIAN 1997

CAMBI 2003

DESJARDINS-RÓMER 1873

DEXHEIMER 2001

EGGER 1952

EGGER 1974

FITZ 1983

FITZ 1993

FITZ 1994

FITZ 1995

FITZ et al. 2001

FRÖHLICH 1892

GoEtTe 1990

HAMPEL 1907

HARL, Lupa

HARL-LŌRINCZ 2002

HERDEJÜRGEN 1996

HoFMANN 1905

KoCH-SiCHTERMANN 1982
= T. ADAmiK: Megjegyzések a Daru utcai sírvershez (Remarks on the metrical epitaph from Daru Street). ArchÉrt 103 (1976) 203-206.

= T. AdAmiK: Aelia Sabina, vale (CE 489). ArchÉrt 105 (1978) 184-188.

= G. AlFöLdY: Epigraphische Studien 4. Köln 1967.

= L. BALLA: Római szarkofág Debrecenben (A Roman sarcophagus at Debrecen). ArchÉrt 89 (1962) $188-191$.

= L. BARKóCZI: Brigetio. DissPann II.22. Budapest 1951.

= L. BARKóczi: The population of Pannonia from Marcus Aurelius to Diocletian. ActaArchHung 16 (1964) 257-356.

= L. BARKócZI: New data on the history of late Roman Brigetio. ActaAntHung 13 (1965) 215-272.

= L. BARKÓCZI: A kelet-pannóniai sírsztélék ábrázolásainak délkeleti és keleti kapcsolatai (Die südöstlichen und orientalischen Beziehungen der Darstellungen an den ostpannonischen Grabstelen). ArchÉrt 109 (1982) 18-50.

= L. BARKócZI: Die südöstlichen und orientalischen Beziehungen der Darstellungen auf den ostpannonischen Grabstelen. MittArchInst 12-13 (1982-1983) 123-151.

= L. BARKóCZI-A. MócSY: Die römischen Inschriften Ungarns (RIU). 2: Salla, Mogentiana, Mursella, Brigetio. Budapest-Bonn 1976.

= L. BARKÓCZI-S. SOPRONI: Die römischen Inschriften Ungarns (RIU). 3: Brigetio (Fortsetzung) und die Limesstrecke am Donauknie. Budapest-Bonn 1981.

= G. BAUCHHENß: Barbaren oder Attis. In: Akten des IV. Internationalen Kolloquiums über Probleme des provinzialrömischen Kunstschaffens, 8.-12. 5. 1995. Situla 36. Ljubljana 1997, 43-51.

= É. BóNIS: Későrómai üvegleletek Aquincumból (Trouvailles de verrerie à Aquincum datant de l'époque de la Romanité tardive). BudRég 14 (1945) 561-572.

= L. Borhy-B. FeHÉR-P. Kovács et al.: Tituli Aquincenses. 2: Tituli sepulcrales et alii Budapestini reperti. Budapest 2010.

= F. BREIN: Bücher auf Grabsteinen. RÖ 1 (1973) 1-5.

= F. BüCHELER-E. LOMMATZSCH: Carmina latina epigraphica. Leipzig 1885-1926.

= J. BURIAN: Brigetio. DNP 2. 1997, 777 s. v.

$=$ N. CAMBI: Attis or someone else on funerary monuments from Dalmatia. In: Romanisation und Resistenz. Akten des VII. Internationalen Kolloquiums über Probleme des provinzialrömischen Kunstschaffens, Köln, 2.-6. 5. 2001. Mainz 2003, 511-520.

= E. DeSJARDins-F. RÓMER: Monuments épigraphiques au Musée National Hongrois. Budapest 1873.

= D. DeXHEIMER: Zur Deutung von Attisfiguren auf Grabaltären Oberitaliens. In: Die Maastrichter Akten des 5. Internationalen Kolloquiums über das provinzialrömische Kunstschaffen im Rahmen des CSIR. Maastricht 2001, 107-113.

= R. EGGER: Epikureische Nachklänge aus Aquincum. JÖAI 39 (1952) 145-150.

= G. EGGER: A római kőfaragás és kőszobrászat Magyarországon. [Römisches Steinmetzhandwerk und Skulptur in Ungarn] Budapest 1974.

= J. FITZ: Honorific titles of Roman military units in the $3^{\text {rd }}$ century. Budapest 1983 .

= J. FITZ: Die Verwaltung Pannoniens in der Römerzeit. 2. Budapest 1993.

= J. FITZ: Die Verwaltung Pannoniens in der Römerzeit. 3. Budapest 1994.

= J. FITZ: Die Verwaltung Pannoniens in der Römerzeit. 4. Budapest 1995.

= J. FITZ-A. MócsY-S. SOPRONI: Die römischen Inschriften Ungarns. 6: Das Territorium von Aquincum, die Civitas Eraviscorum und die Limesstrecke Matrica-Annamatia und das Territorium von Gorsium. Budapest-Bonn 2001.

= R. FRÖHLICH: Aquincumnak római feliratai [Römische Inschriften von Aquincum]. BudRég 4 (1892) $125-156$.

= H. R. GoETTE: Studien zu römischen Togadarstellungen. Mainz 1990.

= J. HAMPEL: Emlékek és leletek. A pannoniai síremlékek áttekintő osztályozása [Denkmäler und Funde. Ein Überblick der Klassifizierung der pannonischen Grabdenkmäler]. ArchÉrt 27 (1907) $333-341$.

= O. HARL-F. HARL: www//ubi-erat-lupa.org

= F. HARL-B. LŐRINCZ: Das römische Lapidarium in der Festung Komárno. Komárno-Wien 2002.

$=$ H. HerdeJÜRGEN: Stadtrömische und italische Girlandensarkophage. Die Sarkophage des ersten und zweiten Jahrhunderts. Die antiken Sarkophagreliefs 6.2.1. Berlin 1996.

= H. Hofmann: Römische Militärgrabsteine der Donauländer. Sonderschriften des Österreichischen Archäologischen Instituts 5. Wien 1905.

= G. Koch-H. Sichtermann: Die römischen Sarkophage. München 1982. 
KORBULY 1934

KovÁCS 2001

KovÁcs 2005

KovÁCs et al. 2007

KRANZ 1984a

KRANZ 1984b

KRANZ 1986

KUZSINSZKY 1899a

KUZSINSZKY 1899b

KUZSINSZKY 1925

KUZSINSZKY 1934

LŐRINCZ 2001

LOŽAR 1927

Mócsy 1962

Mócsy 1969

Mócsy 1974

NAGY 1920-1922

NAGY 1928

NAGY 1939

NAGY 1942

NAGY 1945

NAGY 1950a

NAGY $1950 b$

NAGY 1963

NAGY 1971

NAGY 1987-1988

NAGY-BicZÓ 1998

NÉMETH 1971

NÉMETH 1999

PARRAGI 1963

PARRAGI 1964

PAUlOVICS 1927

PETŐ 1976

PINTERović 1978

PochMARSKi 1983/1984 POCHMARSKI 1985/1986
= G. Korbuly: Aquincum orvosi emlékei (Die ärztlichen Denkmäler von Aquincum). DissPann I.3. Budapest 1934.

= P. KovÁcs: Corpus inscriptionum Graecarum Pannonicarum. Hungarian polis studies 8. Debrecen 2001.

= P. KovÁcs: Tituli romani in Hungaria reperti. Budapest-Bonn 2005.

= P. KovÁCs et al.: Corpus inscriptionum Graecaraum Pannonicarum 3. Hungarian polis studies 15. Budapest-Debrecen 2007.

= P. KranZ: Jahreszeiten-Sarkophage. Die antiken Sarkophagreliefs 5.4. Berlin 1984.

= P. KRANZ: Ein Motiv nordöstlicher Provenienz auf stadtrömischen Sarkophagen nachgallienischer und frühtetrarchischer Zeit. MWPr 1984, 163-170.

= P. KRANZ: Die Grabmonumente von Šempeter. BJb 186 (1986) 193-239.

= B. KuZsinszKY: Aquincum római feliratai [Römische Inschriften von Aquincum] 3. BudRég 6 (1899) 111-150

= V. KuZSINSZKY: Funde aus Ungarn. JÖAI 2 (1899) Beibl. 51-72.

= B. KuZsinszKY: Aquincum. Budapest 1925.

= V. KuZsInsZKY: Aquincum. Ausgrabungen und Funde. Budapest 1934

= B. LŐRINCZ: Die römischen Hilfstruppen in Pannonien während der Prinzipatszeit. 1: Die Inschriften. Wien 2001.

$=$ R. LoŽAR: Studien zu den römischen Sarkophagen von Noricum und Pannonien. (Ungedr. Diss.) Wien 1927.

= A. Mócsy: Pannonia. RE Suppl. IX. Stuttgart 1962, 515-776 s. v.

= A. Mócsy: Pannonia-Forschung 1964-1968. ActaArchHung 21 (1969) 340-375.

= A. Mócsy: Pannonia and Upper Moesia. Provinces of the Roman Empire. London-Boston 1974.

= L. NAGY: Az Országos Magyar Régészeti Társulat Évkönyve = Jahrbuch der Ungarischen Archäologischen Gesellschaft 1, 1920-1922

= L. NAGY: Pelta díszítés a pannoniai kőemlékeken [Peltenornament auf pannonischen Steindenkmälern]. ArchÉrt 42 (1928) 68-95.

= L. NAGY: A szír és kisázsiai vonatkozású emlékek a Duna középfolyása mentében [Denkmäler mit syrischem und kleinasiatischem Bezug am Mittellauf der Donau]. ArchÉrt 52 (1939) 115-147.

= L. NAGY: Budapest története [Geschichte von Budapest] I/2. Budapest 1942.

= L. NAGY: A budai hegyvidék újabb szórványos sírleletei (Recenti ritrovamenti sporadici di sepolture nei dintorni di Buda). BudRég 14 (1945) 535-560.

$=\mathrm{T}$. NAGY: Római kőemlékek Transaquincum területéről (Roman stone monuments from Transaquincum). BudRég 15 (1950) 357-388.

= T. NAGY: A sárkeszi mithraeum és az aquincumi Mithra-emlékek (Le mithréum de Sárkeszi et les monuments mithraiques d'Aquincum). BudRég 15 (1950) 46-120.

$=$ T. NAGY: Quelques aspects de la romanisation dans la Pannonie orientale. In: Le rayonnement des civilisations grecque et romaine sur les cultures périphériques. $8^{\mathrm{e}}$ Congrès international d'Archéologie classique. Paris 1963, 375-381.

= T. NAGY: Köfaragás és szobrászat Aquincumban (Taille de pierre et sculpture à Aquincum). BudRég 22 (1971) 103-160.

= T. NAGY: Vettia Fortunata szarkofágja és mellékletei (Der Sarkophag von Vettia Fortunata und seine Beigaben). ArchÉrt 114-115 (1987-1988) 236-242.

= M. NAGY-P. Biczó: Hungarian National Museum. Lapidarium. Budapest 1998.

= M. NÉMETH: Vezető az Aquincumi Múzeum kőtárában [Führer im Lapidarium des Aquincum-Museums]. Budapest 1971.

= M. NÉMETH: Vezető az Aquincumi Múzeum kőtárában [Führer im Lapidarium des Aquincum-Museums]. Budapest 1999.

= G. PARRAgI: A Bogdáni úton feltárt későrómai temető (Spätrömischer Friedhof in der BogdániStraße). BudRég 20 (1963) 311-326.

= G. PARRAgi: Újabb késő-római leletek a Bécsi úton (Neuere spätrömische Funde auf der BécsiStraße). BudRég 21 (1964) 215-238.

= I. PAulovics: A dunapentelei római telep [Die römische Siedlung von Dunapentele]. ArchHung 2. Budapest 1927.

= M. PETÕ: Római kori sírépítmény és szentély darabjai Csillaghegyen (Fragments of a Roman funerary monument and shrine at Csillaghegy). BudRég 24 (1976) 215-221.

= D. PinTERović: Mursa i njeno područje u antičko doba (Mursa und sein Raum in der Zeit der Antike). Osijek 1978.

= E. PoCHMARSKI: Girlandenhaltende Eroten in Noricum und Pannonien. RÖ 11/12 (1983/84) 225-278.

= E. Pochmarski: Nachtrag zu den ,girlandenhaltenden Eroten“. RÖ 13/14 (1985/86) 243-262. 
POCHMARSKI 1997

POCHMARSKI 1998

POCHMARSKI 2001

POCHMARSKI 2004

PochMARSKI-NAGELE 1992

PóCZY 1969

PóCZY 1974

PÓCZY 1976

Póczy 1997

RÉVAY 1943

RITTERLING 1925

ROBERT 1904

RÓMER 1863

SCHÖN-WITTKE 2000

SOPRONI 1979

SZILÁGYI 1955

SZILÁGYI 1963

SZILÁGYI 1965

SZILÁGYI 1967

SZIRMAI 1985

SZIRMAI 1993

UBL 1969

WELLNER 1971

ZINGERLE 1922-1924
= E. Pochmarski: Neue Forschungen zur Chronologie der provinzialrömischen Plastik in Noricum. In: Komos. Festschrift für Th. Lorenz. Wien 1997, 207-214.

= E. POCHMARSKI: Überlegungen zur Chronologie der pannonischen Sarkophage. In: Akten des Symposions „125 Jahre Sarkophag-Corpus“, Marburg/Lahn 4.-7. 10. 1995. Sarkophag-Studien 1. Mainz 1998, 182-200.

= E. Pochmarski: Zur Ikonographie und Chronologie der römischen Sarkophage aus Brigetio. In: Akten des 6. Internationalen Kolloquiums über Probleme des provinzialrömischen Kunstschaffens, Budapest, 11.-15. 5. 1999. BudRég 34 (2001) 201-221.

= E. POCHMARSKI: Das sagum - urtrachtlicher keltischer Umhang und/oder römischer Uniformmantel. In: Ad fontes! Festschrift G. Dobesch. Wien 2004, 571-578.

= M. Pochmarski-Nagele: Die dionysischen Reliefs und ihre Vorbilder. Wien 1992.

= K. Sz. Póczy: Aquincum. Budapest 1969.

= K. Sz. Póczy: Aquincum. Budapest 19742 .

= K. Sz. PóczY: Städte in Pannonien. Budapest 1976.

= K. Sz. Póczy: Berufsmusiker aus pannonischen Städten. In: Komos. Festschrift für Th. Lorenz. Wien 1997, 215-219.

= J. RÉVAY: Lupus, az aquincumi költő (Lupus, il poeta di Aquincum). ArchÉrt U.F. 4 (1943) 144-148.

= E. RitTERLING: Legio. RE XII.2. Stuttgart 1925, 1329-1829 s. v.

= C. RoberT: Die antiken Sarkophag-Reliefs (=ASR) 3.2. Berlin 1904.

= F. RóMER: Pannoniai újabb kiadatlan feliratok. [Neue unpublizierte Inschriften aus Pannonien] ArchKözl 3 = Ú.F.1 (1863) 156.

= F. SCHÖN-A. WiTtKe: Pannonia. DNP I9. 2000, 250-256 s. v.

= S. Soproni: Municipium Halicanum. FolArch 30 (1979) 91-97.

= J. SzILÁGYI: A római kori ásatások fontosabb eredményei Budapest területén és az Aquincumi Múzeum értékesebb gyarapodásai az 1951/53. években (Wichtige Ergebnisse römerzeitlicher Ausgrabungen im Gebiet von Budapest und wertvolle Bereicherungen des Museums in Aquincum 1951/53). BudRég 16 (1955) 387-426.

= J. G. SZILÁGYI: Megjegyzések az új szentendrei verses feliratról (Remarks to the recently discovered verse inscription from Szentendre). ArchÉrt 90 (1963) 189-194.

= J. SzILÁGYI: Kőfeliratok az Aquincumi Múzeum régi gyűjtéséből (Steininschriften aus der alten Sammlung des Museums von Aquincum) 1. ArchÉrt 92 (1965) 182-191.

= J. SZILÁGYI: Kőfeliratok az Aquincumi Múzeum régi gyűjtéséből (Steininschriften aus der alten Sammlung des Museums von Aquincum ) 2. ArchÉrt 94 (1967) 70-79.

= K. SzIRMAI: Későrómai sírok az aquincumi canabae északi részén (Spätrömische Gräber im nördlichen Teil der Aquincumer Canabae). ArchÉrt 112 (1985) 221-239.

= K. SzIRMAI: Eisengefäße in den spätrömischen Aquincumer Gräbern. In: J. Arce-F. Arce: Bronces y religión romana. Actas del XI Congreso internacional de bronces antiguos, Madrid, mayo-junio 1990. Madrid 1993, 421-427.

$=$ H. UBL: Waffen und Uniform des römischen Heeres der Prinzipatsepoche nach den Grabreliefs Noricums und Pannoniens. (Ungedr. Diss.) Wien 1969. Unveränderter Druck: Wien 2013. Austria Antiqua 3.

= I. WELLNER: Leletmentések az aquincumi canabae déli szélénél (Bergungsgrabungen am südlichen Rand der Aquincumer Canabae). BudRég 22 (1971) 411-418.

= J. ZINGERLE: Kyknos-Relief in Wien. JÖAI 21/22 (1922-1924) 229-250. 